\title{
PROCEDIMIENTOS DESCENTRALIZADOS DE AUTORIZACIÓN DE MEDICAMENTOS \\ EN EL DERECHO DE LA UE: PROBLEMAS \\ DE TUTELA JUDICIAL EFECTIVA
}

JUAN ANTONIO CHINCHILLA PEINADO'

juanantonio.chinchilla@uam.es

Cómo citar/Citation

Chinchilla Peinado, J. A. (2020).

Procedimientos descentralizados de autorización de medicamentos en el derecho de la UE: problemas de tutela judicial efectiva. Revista de Derecho Comunitario Europeo, 67, $921-962$. doi: https://doi.org/10.18042/cepc/rdce.67.05

\section{Resumen}

La regulación europea de los procedimientos de autorización de medicamentos diseña, junto con un modelo de ejecución directa, varios tipos de ejecución por parte de los Estados miembros, con distintos grados de colaboración entre ellos. El denominado "procedimiento descentralizado" se configura como un procedimiento en red (compuesto) horizontal, donde los Estados miembros participan en pie de igualdad en la valoración del riesgo científico, otorgando cada uno de ellos la correspondiente autorización de comercialización. Esa configuración plantea problemas de tutela judicial de los terceros competidores como consecuencia del principio de doble exclusividad de la competencia del Tribunal de Justicia de la Unión Europea y los

1 Profesor titular de Derecho Administrativo de la Universidad Autónoma de Madrid, https://orcid.org/0000-0003-2686-6753. En el presente trabajo se recogen resultados de la investigación realizada en el contexto del Proyecto de $\mathrm{I}+\mathrm{D}$ correspondiente al Programa estatal de fomento de la investigación científica y técnica de excelencia, Relaciones jurídicas transnacionales en el mercado interior y justicia administrativa (DER 2017-84500-P), dirigido por J. Agudo González, profesor titular de Derecho Administrativo de la UAM, 2018-20. 
órganos jurisdiccionales nacionales. Los posibles déficits de control judicial deben ser resueltos a la luz del principio de cooperación leal, para dar lugar a un sistema de control descentralizado articulado sobre la base de un diálogo entre los órganos judiciales nacionales.

\title{
Palabras clave
}

Unión administrativa; procedimientos compuestos; tutela judicial; medicamentos.

\section{DECENTRALISED PROCEDURES FOR THE AUTHORISATION OF MEDICINES IN THE EU LAW: SOME PROBLEMS OF EFFECTIVE JUDICIAL PROTECTION}

\begin{abstract}
The European regulation on procedures for the authorisation of medicinal products, together with a model of direct enforcement, designs several types of enforcement by Member States, with varying degrees of collaboration between them. The so-called "decentralised procedure" is configured as a horizontal (compound) network procedure, where the Member States participate on an equal footing in the assessment of scientific risk, each of them granting the corresponding marketing authorisation. This configuration raises problems of judicial protection of third party competitors as a result of the principle of double exclusivity of the competence of the Court of Justice of the European Union and the national courts. Any shortcomings in judicial control must be resolved in the light of the principle of loyal cooperation, to give rise to a system of decentralised control based on dialogue between the national courts.
\end{abstract}

\section{Keywords}

European composite administration; composite administrative procedures; judicial review; medicines.

\section{PROCÉDURES DÉCENTRALISÉES D'AUTORISATION DES MÉDICAMENTS DANS LE DROIT DE L'UE: PROBLÈMES DE PROTECTION JURIDICTIONNELLE EFFECTIVE}

\section{Résumé}

Le règlement européen relatif aux procédures d'autorisation des médicaments prévoit un modèle d'application directe et plusieurs types d'application par les États membres, avec des degrés de collaboration variables entre eux. La procédure dite «dé- 
centralisée» est configurée comme une procédure horizontale (composée) en réseau, dans laquelle les États membres participent sur un pied d'égalité à l'évaluation du risque scientifique, chacun d'entre eux accordant l'autorisation de mise sur le marché correspondante. Cette configuration pose des problèmes de protection juridictionnelle des tiers concurrents en raison du principe de double exclusivité de la compétence de la Cour de justice de l'Union européenne et des tribunaux nationaux. Les éventuelles défaillances du contrôle juridictionnel doivent être résolues à la lumière du principe de coopération loyale, pour donner naissance à un système de contrôle décentralisé basé sur le dialogue entre les tribunaux nationaux.

\section{Mots clés}

Union administrative; procédures composites; protection judiciaire; les médicaments. 


\section{Sumario}

I. INTRODUCCIÓN. II. AUTORIZACIÓN DE MEDICAMENTOS PARA USO HUMANO Y PARA USO VETERINARIO. REGULACIÓN EUROPEA Y UTILIZACIÓN EFECTIVA EN EL MERCADO ÚNICO: 1. La autorización de medicamentos como sector de referencia en la unión administrativa europea. 2. Los procedimientos de autorización conforme al Derecho europeo. Los márgenes de apreciación en los procedimientos compuestos. 3. La efectiva utilización de los distintos procedimientos. Preponderancia del procedimiento descentralizado. III. PROCEDIMIENTO DESCENTRALIZADO Y SISTEMAS DE RECURSOS (ADMINISTRATIVOS Y JUDICIALES) DE LOS ESTADOS MIEMBROS. LA PROYECCIÓN DEL DERECHO EUROPEO SOBRE EL SISTEMA DE TUTELA JUDICIAL NACIONAL: 1. Tutela de usuarios o terceros imparciales en la fase administrativa de otorgamiento de la autorización. 2. La atribución de legitimación a los terceros competidores. ¿̇Efectos transnacionales o atribución funcional de responsabilidades? La garantía del principio de uniformidad y el control judicial descentralizado. 3. La tutela ante el procedimiento de revisión. 4. La tutela del solicitante al que se le desestima una autorización de comercialización de un medicamente genérico. IV. EL PROCEDIMIENTO DESCENTRALIZADO COMO REFLEJO DE UNA UNIÓN ADMINISTRATIVA MULTINIVEL. BIBLIOGRAFIA.

\section{INTRODUCCIÓN}

La complejidad regulatoria de los tipos de ejecución del derecho de la Unión Europea ha superado la tradicional dicotomía ejecución directa frente a ejecución indirecta. La realidad de una unión administrativa europea (Schneider, 2008: 26; Ruffert, 2008: 88), que articula diversos procedimientos cooperativos entre los órganos europeos y las Administraciones nacionales y entre estas entre sí, ha dado lugar al concepto de acto transnacional (Ortega Bernardo, 2017: 82) y al acto referencial y el reconocimiento mutuo (Agudo González, 2019: 246), así como a la figura de los procedimientos compuestos (Hofmann, 2019: 3). Este trabajo focaliza su atención en un tipo concreto de procedimiento compuesto, el denominado "procedimiento descentralizado» en materia de autorización de medicamentos, que presenta diferencias sustanciales con las categorías generales descritas por la doctrina, al tratarse de un 
procedimiento donde las distintas Administraciones nacionales intervienen en pie de igualdad, al menos en la fase decisiva del mismo, y que concluye con diversas resoluciones autorizadoras nacionales, condicionadas por esa intervención conjunta previa. Esa configuración como procedimiento compuesto horizontal proyecta diversos interrogantes desde la perspectiva del derecho a la tutela judicial (protección legal) efectiva de terceros interesados. Frente a la posible existencia de actuaciones nacionales exentas de control jurisdiccional como consecuencia de las reglas de reparto competencial entre el Tribunal de Justicia de la Unión Europea (TJUE) y los tribunales nacionales, lo cierto es que la interacción informal entre los órganos de la jurisdicción contencioso-administrativa de los distintos Estados miembros permite afirmar la existencia de un control judicial descentralizado que garantiza de forma efectiva el cumplimiento del principio del Estado de derecho. Aquí se dejan al margen las consideraciones relativas a los costes económicos y de comprensión del ordenamiento legal que pueden constituir una barrera de acceso al control jurisdiccional cuando ese tercero debe recurrir ante un órgano jurisdiccional de un tercer Estado miembro diferente al de su lugar de residencia o establecimiento de la empresa (De Lucia, 2016: 103), que en el caso de las autorizaciones de medicamentos resultan menores, dado el carácter de grandes corporaciones de carácter multinacional de los operadores.

\section{AUTORIZACIÓN DE MEDICAMENTOS PARA USO HUMANO Y PARA USO VETERINARIO. REGULACIÓN EUROPEA Y UTILIZACIÓN EFECTIVA EN EL MERCADO ÚNICO}

\section{LA AUTORIZACIÓN DE MEDICAMENTOS COMO SECTOR DE REFERENCIA EN LA UNIÓN ADMINISTRATIVA EUROPEA}

El derecho europeo en el ámbito de los medicamentos, sean para uso humano o para uso veterinario, en cuanto sectores de referencia de la unión administrativa como forma de organización del mercado interior ${ }^{2}$, adopta como elemento estructural la prohibición de comercialización de cualquier medicamento que no haya obtenido previamente la correspondiente

2 Que muestra diferentes modelos de unión administrativa, existiendo notables diferencias tanto entre los diferentes sectores como entre los distintos tipos de procedimientos dentro de un concreto sector (Di Lucia, 2018: 100). 
autorización de comercialización ${ }^{3}$ (otorgada por la Comisión o por la autoridad nacional $)^{4}$. Tras la obtención de la autorización de comercialización, el operador debe acordar con cada Estado miembro el precio de venta del producto, lo que es una competencia exclusiva de los Estados ${ }^{5}$.

Las diferentes normas europeas que regulan las autorizaciones de comercialización de medicamentos articulan dos intereses contrapuestos (Izquierdo Carrasco, 2018: 363). De una parte, la protección de la salud pública (inocuidad y seguridad para las personas frente a beneficios terapéuticos), incorporando normas procedimentales y organizativas ${ }^{6}$ que permiten autorizar solo aquellos medicamentos que acrediten un riesgo nulo o, al menos tolerable, para la salud humana y resulten eficaces en la lucha frente a las diversas enfermedades (principio de precaución). En la adopción de sus decisiones, las Administraciones competentes deben primar la protección de los intereses de los pacientes. La desmaterialización de la dirección normativa de la Administración en un ámbito de gestión de riesgos ${ }^{7}$ se compensa, en

3 Cfr. Directiva 2001/83/CE del Parlamento Europeo y del Consejo, de 6 de noviembre de 2001, por la que se establece un código comunitario sobre medicamentos para uso humano (art. 6) (DO L 311, de 28 de noviembre de 2001, pp. 67-128); Reglamento (CE) 726/2004 del Parlamento Europeo y del Consejo de 31 de marzo de 2004 por el que se establecen procedimientos comunitarios para la autorización y el control de los medicamentos de uso humano y veterinario y por el que se crea la Agencia Europea de Medicamentos (art.3) (DO L 136, de 30 de abril de 2004, pp. 1-33), y Reglamento (UE) 2019/6 del Parlamento Europeo y del Consejo de 11 de diciembre de 2018 sobre medicamentos veterinarios (art. 5) (DO L 4, de 7 de enero de 2019, pp. 43-167).

4 No puede importarse un medicamento que cuente con la correspondiente autorización de comercialización en un Estado miembro si el Estado donde pretende importarse no cuenta también con la previa autorización, Sentencia del Tribunal de Justicia de 27 de octubre de 2016, Audace y otros, C-114/15, EU:C:2016:813.

5 Sobre las diferencias en la fijación de precios y su incidencia sobre el mercado interior, Kyle (2019: 114).

6 La densidad material de la regulación en este sector es, esencialmente, inexistente o muy tenue. No se establecen reglas de programación condicional o final que dirijan materialmente y de forma suficiente la actuación administrativa, sino normas organizativas y procedimentales que permitan garantizar que la relación beneficio-riesgo sea favorable y que la eficacia terapéutica esté suficientemente justificada. Sobre tal modalidad de dirección de la actuación administrativa, Rodríguez de Santiago (2016: 27).

7 Lo que resulta inevitable, ya que cada medicamento cuenta con una composición cualitativa y cuantitativa, con unos determinados principios activos y concretas pautas de dosificación, entre otros aspectos, lo que configura como un producto singular que 
el aspecto organizativo, confiriendo a una autoridad administrativa independiente y a la red de autoridades en la que se integra (conformadas por expertos) la competencia para analizar y evaluar la eficacia, los riesgos y la calidad de los medicamentos, lo que ha generado una adecuada confianza en los ciudadanos (Alonso de León, 2017: 190). En el plano procedimental, la desmaterialización se supera a través de la articulación de procedimientos donde la clave reside en la aportación de evidencias científicas que permitan realizar un efectivo análisis del riesgo, mediante procedimientos abiertos que permitan la participación y comunicación entre las Administraciones de los Estados miembros, las estructuras europeas, los expertos científicos, las empresas que operan en el sector y la opinión pública (Izquierdo Carrasco, 2018: 366; Schmidt-Aßmann, 2003: 176). Todo ello como concreción del principio de buena administración. Y en ese procedimiento, la responsabilidad primaria de aportar los datos fácticos sobre el riesgo (el análisis del riesgo) ${ }^{8}$ recae en el operador que solicita la autorización ${ }^{9}$, quien adquiere un papel relevante en el proceso de construcción de la norma de conducta que aplica la Administración, sin perjuicio de que el órgano competente para otorgar la autorización pueda incorporar las observaciones de terceros que permitan comprobar, en interés de la salud pública, que dispone de toda la información sobre la evaluación científica del medicamento, tanto si resulta favorable al producto como si la misma es negativa ${ }^{10}$.

De otra parte, esas normas toman en cuenta la protección de los intereses comerciales de los fabricantes de medicamentos ${ }^{11}$, que invierten en innovación

no puede ser objeto de una específica reglamentación general, como precisa Izquierdo Carrasco (2018: 394).

8 Izquierdo Carrasco (ibid.: 402) describe gráficamente esta situación. Es el operador «quien debe analizar los riesgos; debe ofrecer a las autoridades competentes los datos necesarios que respalden la seguridad/eficacia del medicamento; debe supervisar de manera permanente su comercialización y efectos [...] debe [...] adaptarse a la mejor técnica disponible o nuevos datos ofrecidos por la ciencia».

9 El solicitante de la autorización de comercialización debe acompañar su solicitud de toda la información sobre la evaluación científica del medicamento de que se trate, y especialmente la información sobre los resultados de todos los ensayos clínicos efectuados, tanto si resultan favorables al producto como si son desfavorables.

10 En los términos fijados por la Sentencia del Tribunal General de 18 de diciembre de 2003, Olivieri/Comisión y EMEA, T-326/99. EU:T:2003:351.

11 Como precisa Kyle (2019: 112), los mercados farmacéuticos responden a una competencia entre empresas oligopolísticas, donde cada una produce un producto diferenciado protegido por patente para tratar una enfermedad en particular y vende a compradores monopsónicos, en un entorno altamente regulado. 
con objeto de desarrollar nuevas estratégicas de lucha contra las enfermedades. Protección que se logra mediante normas que garantizan derechos de exclusividad durante un plazo razonable para evitar colocarlos en una posición de desventaja competitiva frente a las empresas que elaboran medicamentos genéricos (ya existentes). El reconocimiento de los derechos de exclusividad no es indefinido. Razones de eficiencia y economía conducen a evitar que cada nuevo medicamento deba estar basado en estudios originales y novedosos. Son así razones de orden público las que justifican evitar la repetición sin imperiosa necesidad de las pruebas en personas o animales ${ }^{12}$, lo que permite a terceros competidores aprovecharse de los estudios y análisis previos.

La cuestión que inmediatamente se plantea, en un entorno donde existen importantes intereses competitivos entre los diferentes operadores económicos ${ }^{13}$, es el alcance de la previa autorización administrativa y su tutela judicial, máxime cuando el procedimiento de otorgamiento es configurado por las normas de derecho secundario europeas y por el Tribunal de Justicia de la Unión Europea (Olivieri) ${ }^{14}$ como un procedimiento bilateral, entre el órgano competente que otorga la autorización (sea la Comisión Europea, sea el órgano competente de un Estado miembro) y el solicitante. ¿Existe realmente una desconexión entre la configuración de los procedimientos administrativos de autorización de medicamentos donde participan diversas autoridades de Estados miembros con el fin de lograr una mayor implementación del derecho europeo y los mecanismos de control jurisdiccional, dada la limitación de las normas de control judicial en los procedimientos compuestos? ¿Cómo articular una efectiva garantía del derecho a la tutela judicial efectiva en una Unión administrativa multinivel que actúa a través de procedimientos compuestos? ¿Corresponde la tutela al TJUE o los diversos órganos judiciales de los Estados miembros o existe un espacio inmune a la tutela judicial? La actual arquitectura constitucional de la Unión Europea, y

12 Como precisa, p.ej., el considerando $10 .^{\circ}$ de la Directiva 2001/83/CE de 6 de noviembre de 2001, por la que se establece un código comunitario sobre medicamentos para uso humano, donde tales estudios se consideran innecesarios en el procedimiento de autorización de un medicamento esencialmente similar a un medicamento ya autorizado, por lo que no se exige facilitar los resultados de las pruebas toxicológicas, farmacológicas, o clínicas.

13 Y donde la posición de las empresas farmacéuticas y de las compañías aseguradoras como grupos de presión presentan evidentes riesgos morales. Sobre ello, Kyle (ibid: 111).

14 Sentencia del Tribunal General de 18 de diciembre de 2003, Olivieri/Comisión y EMEA, T-326/99, EU:T:2003:351. 
su sistema jurisdiccional dual afronta aquí un evidente desafío (Brito Bastos, 2020: 64; Alonso de León, 2017: 213).

\section{LOS PROCEDIMIENTOS DE AUTORIZACIÓN CONFORME AL DERECHO EUROPEO. LOS MÁRGENES DE APRECIACIÓN EN LOS PROCEDIMIENTOS COMPUESTOS}

Los medicamentos, desde la perspectiva de la regulación de su autorización para su puesta en el mercado, pueden diferenciarse en dos grandes categorías de productos (Langedijk et al, 2016: 47). De una parte, aquellos que incorporan una nueva sustancia activa, que deben ser autorizados por la Comisión a través de un procedimiento centralizado. De otra parte, aquellos cuya composición está conformada por sustancias activas ya conocidas y que, generalmente, no están protegidos por los derechos derivados de una patente. Los medicamentos genéricos se sitúan en esta segunda categoría. Estos medicamentos se autorizan a través de un procedimiento descentralizado o a través de un procedimiento de reconocimiento mutuo, donde no resulta necesario realizar nuevos estudios clínicos o preclínicos en animales y humanos, al aprovechar los ya efectuados para el otorgamiento de la autorización de comercialización del medicamento de referencia ${ }^{15}$.

Los procedimientos de autorización de medicamentos y su efectiva utilización ponen de relieve cómo el sistema europeo se presenta cada vez más interconectado (Brito Bastos, 2018: 101) ${ }^{16}$ como respuesta a la pérdida de competitividad de la industria farmacéutica europea en la década de los noventa del siglo pasado, lo que ha conducido a un proceso de armonización y regulación uniforme ${ }^{17}$. Así, en la construcción de la unión administrativa en el sector de los medicamentos cabe identificar una primera fase en ese proceso de construcción, donde el elemento central es la institución del reconocimiento mutuo ${ }^{18}$ que permite la apertura horizontal de los ordenamientos

15 Como señala la Sentencia del Tribunal de Justicia 18 de junio de 2009, Generics, C-527/07, EU:C:2009:37, para aprovecharse de los efectos de esos estudios el solicitante de la autorización de un medicamento genérico debe acreditar que el medicamento de referencia obtuvo su autorización conforme a los requerimientos de las normas europeas.

16 Un ejemplo de dicha interconexión, en materia de relaciones laborales, en Domínguez Martín (2020: 1).

17 Alonso de León (2017: 186).

18 Configurado como un método de selección y aplicación de normas, ante la falta de complitud del ordenamiento nacional, que concluye en el reconocimiento de la norma de otro Estado miembro (principio del país de origen), directamente 
jurídicos nacionales a través del establecimiento de pasarelas entre ellos (De Lucia, 2009; 4; Agudo González, 2019: 228), configuradas sobre la base de requisitos de comparabilidad o equivalencia de los ordenamientos nacionales prefigurados por las directivas, existiendo un marco normativo fragmentado (Siegel, 2016: 121). El principio de reconocimiento mutuo persigue así lograr una integración profunda del mercado a la vez que respeta las diversidades dentro de los Estados miembros (De Lucia, 2016: 92). Ciertamente estas directivas incorporaban unas regulaciones de máximos que impedían que los Estados miembros adoptasen una legislación nacional con niveles de seguridad más elevados con el argumento de una mayor protección a los ciudadanos (Izquierdo Carrasco, 2018: 409).

La segunda fase, que concentra la normativa dispersa, se construye fundamentalmente a través de la figura del reglamento, que incorpora una regulación detallada sin espacio para la regulación nacional, y donde el foco se sitúa en los procesos descentralizados de autorización, en la ejecución cooperativa de los Estados miembros. El elemento clave de ese nueva fase de la unión administrativa es la autorización descentralizada en cuanto tipo regulativo centralizado y de ejecución descentralizada. Este tipo coexiste con un tipo regulativo y de ejecución centralizada (donde la regulación completa es fijada por el derecho europeo a través de un reglamento, otorgándose las autorizaciones directamente por la Comisión, en un procedimiento donde intervienen las agencias reguladoras europeas y los Estados miembros, y donde el control judicial corresponde al TJUE), así como con un tipo regulativo compartido y de ejecución nacional (en el que la regulación armonizada es fijada por el derecho europeo a través de directivas que deben ser traspuestas y complementadas por el derecho nacional, otorgándose las autorizaciones por cada Estado miembro conforme a su ordenamiento, sin perjuicio del reconocimiento mutuo).

En la primera fase, la falta de una programación material detallada ha permitido obtener resultados diferentes en función de cuál sea el Estado de referencia, ocasionado un proceso de elección por parte de los operadores económicos de aquellos Estados más proclives a otorgar las autorizaciones (Izquierdo Carrasco, 2018: 413; Bombillar Sáez, 2010: 356). Tras la adopción común de las monografías por EMA, segunda fase, la elección del Estado de referencia no se realiza por razones normativas, sino por razones de la mayor o menor eficiencia temporal en la gestión del procedimiento de autorización

o mediante la intermediación de un acto aplicativo nacional. Sobre ello, Agudo González (2019: 233). 
por parte del órgano administrativo nacional competente (Kyle, 2019: 118) ${ }^{19}$. Aquí ya no se produce un fenómeno de selección y aplicación de la norma del país de origen. No hay un control del cumplimiento de los requisitos fijados por la propia normativa nacional (home country control) en un sector material más o menos armonizado por el derecho europeo.

De forma sintética, y analizando de forma conjunta los dos grupos normativos, cabe apreciar la existencia de cuatro procedimientos diferenciados para obtener una autorización de comercialización de medicamentos para uso humano o para uso veterinario. La tensión entre transnacionalidad y supranacionalidad, entre fragmentación y unidad en la implementación del derecho europeo se articula a través de un procedimiento de ejecución directa por parte de la Comisión, y de tres procedimientos donde debe obtenerse una autorización nacional en los países donde pretenda comercializarse. La cooperación multinivel presenta aquí tanto una dimensión vertical como una dimensión horizontal, alejada del principio de jerarquía (Chinchilla Peinado, 2015: 150).

- Autorizaciones de comercialización centralizadas (centralised marketing authorisations). Válidas en toda la Unión por un periodo de cinco años ${ }^{20}$. Este tipo de autorización resulta obligatoria para determinados medicamentos de uso humano ${ }^{21}$ y opcional en otros supuestos para determinados medicamentos de uso humano ${ }^{22}$. Aquí todo el procedimiento se verifica a nivel europeo. El mismo se inicia mediante la presentación de una solicitud ante la Agencia Europea del Medicamento (EMA), que realiza

19 Alemania, Reino Unido, Suecia y Holanda son los Estados de referencia con mayor número de solicitudes de autorización de nuevos medicamentos, mientras que para las solicitudes de medicamentos genéricos son Alemania, Reino Unido, Dinamarca, Suecia y Holanda.

20 Arts. 42-44 Reglamento (UE) 2019/6, y arts. 3-14 Reglamento (CE) 726/2004.

21 Para los medicamentos de uso humano cuando se trate de medicamentos de alta tecnología, medicamentos huérfanos o medicamentos que contengan una sustancia activa totalmente nueva en la Unión Europea para el tratamiento de determinadas patologías como son el síndrome de inmunodeficiencia adquirida, cáncer, trastornos neurodegenerativos y diabetes.

22 Opcionalmente, el procedimiento centralizado se podrá utilizar cuando se trate de medicamentos que contengan una nueva sustancia activa que no estuviera autorizada en la Unión Europea en la fecha de entrada en vigor del Reglamento, y aquellos en que el solicitante demuestra que dicho medicamento constituye una innovación significativa desde el punto de vista terapéutico, científico o técnico, o que la concesión de una autorización presenta para los pacientes un interés en el ámbito comunitario. 
una evaluación de los riesgos y beneficios desde la perspectiva científica. En concreto, dicho dictamen es realizado por el Comité de Medicamentos de Uso Humano (CHMP) o por el Comité de Medicamentos de Uso Veterinario (CVMP), integrado por miembros designados por cada uno de los Estados miembros ${ }^{23}$. Dicho dictamen sirve de fundamento (no vinculante) a la resolución (decisión) que adopta la Comisión mediante un acto de ejecución (conforme al procedimiento de examen ${ }^{24}$ ). Por tanto, el procedimiento centralizado implica la participación de todos los Estados miembros en la evaluación científica, aunque es la Comisión quién adopta formalmente la decisión. El dictamen de la EMA constituye un "trámite intermedio cuyo objetivo es preparar la decisión final» (no tiene carácter vinculante), por lo que no fija definitivamente la posición de la Comisión. Consecuentemente, no es un acto directamente impugnable en los términos del art. 263 TFUE, pero en la medida en que el contenido del dictamen de la EMA y los informes de evaluación en que se basa forman parte de la motivación de la decisión de la Comisión, su corrección puede ser examinada en el marco de la pretensión de anulación de la decisión de la Comisión ${ }^{25}$. Posteriormente, la EMA hace público su dictamen, debidamente eliminada la información comercial confidencial, e incorporando un resumen redactado de forma comprensible para el público ${ }^{26}$. La autorización, única se configura así como un

23 Committee for Medicinal Products for Human Use, Rules of Procedure, EMEA/ 45110/2007 y Committee for Medicinal Products for Veterinary Use, Rules of Procedure, EMEA/CVMP/422/04. En ambos casos, cada Comité designa a una autoridad nacional como ponente (no de forma rotatoria, sino sobre la base de criterios objetivos que posibiliten el nombramiento del mejor experto) para que prepare el informe de evaluación científica. Generalmente se designa a un componente que, o bien preparará una evaluación crítica del informe elaborado por el ponente o bien redacta su propio informe de evaluación, dependiendo de la elección del Comité. Sobre la base del informe, el Comité adopta un dictamen favorable o desfavorable. La decisión suele adoptarse por consenso, requiriéndose en caso contrario la mayoría de los miembros del Comité. Si el dictamen es desfavorable, el solicitante podrá solicitar un nuevo examen. Sobre este procedimiento, Röttger-Wirtz y Eliantonio (2019: 402); Alonso de León (2017: 189).

24 Art. 5 Reglamento (UE) 182/2011. El CHMP o CVMP expresan su opinión por mayoría cualificada.

25 Sentencia del Tribunal General de 18 de diciembre de 2003, Olivieri/Comisión y EMEA, T-326/99, EU:T:2003:351.

26 Art. 13.3 Reglamento (UE) 726/2004 y art. 44.10 Reglamento (UE) 2019/6. 
acto europeo (Tavares da Silva, 2018: 448), sin perjuicio de la relativa participación de los Estados miembros en ese proceso ${ }^{27}$.

- Autorizaciones nacionales de comercialización (national marketing authorisations). Válidas en un único Estado miembro ${ }^{28}$. Aquí se formula una solicitud ante una concreta autoridad nacional, que tramita y resuelve ese procedimiento conforme a su normativa nacional, sin que exista ninguna participación de otro Estado miembro (Röttger-Wirtz y Eliantonio, 2019: 396). Posteriormente a la autorización, la autoridad nacional publicará el informe de evaluación, una vez eliminada cualquier información comercial confidencial. Tres elementos claves se refieren al medicamento susceptible de ser autorizado: a) no puede proyectarse sobre aquellos medicamentos para los que el procedimiento centralizado resulta obligatorio; b) tampoco puede proyectarse sobre un medicamento que haya obtenido una previa autorización nacional en otro Estado miembro; c) no pueden presentarse simultáneamente solicitudes de autorizaciones nacionales en varios Estados miembros. Este es un sistema de ejecución individual («aislada») del derecho de la Unión, limitándose los efectos de la autorización al territorio del Estado otorgante (Siegel, 2016: 105; Fernández Gaztea, 2018: 280).

- Reconocimiento mutuo de autorizaciones nacionales de comercialización. Cuando ya exista otorgada por una autorización nacional, debe obligatoriamente adoptarse este procedimiento para lograr su autorización en otros Estados miembros ${ }^{29}$. La armonización jurídica se conjuga simultáneamente con una coordinación procedimental, a través de un procedimiento compuesto, para dotar de virtualidad al reconocimiento mutuo en un ámbito sensible para la salud de los ciudadanos (RöttgerWirtz y Eliantonio, 2019: 397). La solicitud del reconocimiento mutuo de la autorización de comercialización ya otorgada se presenta ante el Estado de referencia (el que concedió la primigenia autorización) y ante los Estados interesados. El Estado de referencia remite el informe de evaluación que efectuó, en su caso debidamente actualizado, a las autoridades de los Estados interesados, que deben aprobarlo. Si no hay

27 No parece razonable identificar aquí un supuesto de procedimiento compuesto como proponen Röttger-Wirtz y Eliantonio (2019: 402), al considerar decisiva la participación de los Estados miembros a través de los representantes designados en los Comités que integran la EMA.

28 Para los medicamentos veterinarios, cfr. arts. 46-47 Reglamento (UE) 2019/6. Para los medicamentos de uso humano, cfr. arts. 17-26 Directiva 2001/83/CE.

29 Para los medicamentos de uso humano, cfr. art. 28.2 Directiva 2001/83/CE. Para los medicamentos veterinarios, cfr. arts. 51 y 52 Reglamento (UE) 2019/6. 
alegaciones, el Estado de referencia concluye el procedimiento haciendo constar el acuerdo, y son las autoridades de los Estados interesados las que deben otorgar la autorización de comercialización sobre la base del informe de evaluación. El principio de reconocimiento mutuo implica aquí que los Estados concernidos deben asumir íntegramente el informe de evaluación elaborado por el Estado de referencia (decisión reglada), sin que puedan cuestionar la evaluación científica realizada, requiriendo o realizando una nueva evaluación. Esa es una obligación "clara y precisa» impuesta al Estado interesado $\left(\right.$ Synthon) ${ }^{30}$. La única excepción que justifica apartarse del informe de evaluación debe basarse en la existencia acreditada de un riesgo potencial grave para la salud pública. Todo ello sin perjuicio de la comprobación de la validez de la solicitud de reconocimiento mutuo en cuanto a los requisitos exigidos. La autorización otorgada por el Estado de referencia debe calificarse como un acto nacional, con efectos trasnacionales (Tavares da Silva, 2018: 448; Siegel, 2016: 105; Fernández Gaztea, 2018: 280; López de Castro García-Morato, 2020: 89). De ahí que se afirme que el procedimiento formalizado de reconocimiento mutuo se configura como un procedimiento compuesto horizontal ${ }^{31}$, donde cada Estado concernido adopta su decisión sobre la base de la información y la autorización generadas por el Estado de referencia. Pero en este procedimiento compuesto no existe, en esta fase, ningún "mecanismo de cooperación" estructural entre el Estado de referencia y los Estados concernidos (Röttger-Wirtz y Eliantonio, 2019: 398), más allá del intercambio de información, para la valoración científica del medicamento, sin que pueda cuestionarse la legalidad y corrección de la autorización de comercialización ya otorgada en el Estado de referencia. Se configura así como un mecanismo de "cooperación interhorizontal», al no situarse en pie de igualdad el Estado de referencia respecto de los Estados concernidos (Siegel, 2016: 104).

30 Sentencia del Tribunal de Justicia de 16 de octubre de 2008, Synthon, C-452/06, EU:C:2008:565, donde se precisa que «si un Estado miembro que debe reconocer una autorización ya otorgada por otro Estado miembro pudiese supeditar tal reconocimiento a una segunda apreciación de toda o parte de la solicitud de autorización, el procedimiento de reconocimiento muto establecido por el legislador comunitario quedaría privado totalmente de sentido y se vería gravemente comprometida la realización de los objetivos de la Directiva 2001/83, como la libre circulación de medicamentos en el mercado interior".

31 Alonso de León (2017: 190) lo califica de procedimiento de carácter interestatal regulado directamente por el derecho secundario. 
- Autorizaciones de comercialización descentralizadas (decentralised marketing authorisations). Válidas en cada uno de los países que la otorgan. Este procedimiento debe adoptarse cuando ningún Estado miembro ha concedido previamente una autorización de comercialización de medicamentos que no requieran una autorización centralizada y la solicitud se presenta simultáneamente en varios Estados miembros ${ }^{32}$. El procedimiento se inicia mediante la presentación de la solicitud ante la autoridad competente del Estado miembro de referencia seleccionado por el solicitante (reference Member State), que asume la dirección de la evaluación científica y, simultáneamente, ante las autoridades del resto de Estados miembros interesados (Member States concerned). Se trata, por tanto, de un procedimiento iniciado sobre la base de múltiples y paralelas solicitudes (Röttger-Wirtz y Eliantonio, 2019: 393), que es tramitado de forma conjunta, con la participación de todos los Estados afectados. La autoridad competente del Estado de referencia elabora una propuesta de informe de evaluación, que es remitida a las autoridades de los Estados concernidos para su escrutinio y aprobación conjunta, pudiendo presentar alegaciones cualquiera de los Estados. Si existe acuerdo, el Estado de referencia lo comunica a todos los Estados concernidos, y todos y cada uno de ellos deben conceder una autorización individualizada e idéntica sobre la base del informe de evaluación adoptado conjuntamente. Las autoridades competentes de esos Estados miembros no pueden, al adoptar una decisión sobre la comercialización en su territorio del medicamento, cuestionar el resultado del procedimiento ${ }^{33}$. No debe seguirse ningún orden en el otorgamiento de las diferentes autorizaciones (son decisiones en paralelo, sin ningún orden de precedencia). La primera puede ser otorgada por el Estado de referencia o por cualquier Estado concernido. La autoridad competente del Estado miembro de referencia publicará el informe de evaluación, una vez eliminada cualquier información comercial confidencial. Por el contrario, si el informe de evaluación es desfavorable y no hay alegaciones de los Estados interesados, se acuerda la denegación por el Estado de referencia, que informa al interesado y al resto de Estados interesados. En caso de desacuerdo, por considerar algún Estado que existe un riesgo potencial grave para la salud pública,

32 Para los medicamentos de uso humano, cfr. art. 28.3 Directiva 2001/83/CE. Para los medicamentos veterinarios, cfr. arts. 48-49 Reglamento (UE) 2019/6.

33 Sentencias del Tribunal de Justicia de 14 de marzo de 2018, Astellas, C-557/16, EU:C:2018:181, y de 19 de julio de 2012, Comisión/República Francesa, C-145/11, EU:C:2012:490 — no publicada-. 
la decisión final corresponde a la Agencia Europea del Medicamento. Este procedimiento descentralizado se construye a través de la tramitación de un único procedimiento compuesto y horizontal en red (Alonso de León, 2017: 159), donde intervienen diferentes Administraciones nacionales y que concluye en una primera decisión administrativa de trámite, adoptada por el Estado de referencia, que recibe imputs de los sistemas del resto de Estados miembros concernidos. Aquí sí se establece un «mecanismo de cooperación» estructural entre el Estado de referencia y los Estados concernidos, donde se produce una información y se articula la discusión de posibles diferencias, dando lugar a un espacio de codecisión (Röttger-Wirtz y Eliantonio, 2019: 399). No se produce un reconocimiento mutuo automático y categórico. Se configura como un mecanismo de "cooperación intrahorizontal», en el que se sitúan en pie de igualdad los Estados concernidos y el Estado de referencia (Siegel, 2016: 104). La decisión de cada Estado miembro requiere que previamente, dentro del procedimiento compuesto, haya hecho suya la evaluación científica a través de esa codecisión. La participación de los diferentes Estados se verifica, no conforme a su legislación nacional de procedimiento. Tampoco conforme a la normativa de procedimiento del Estado de referencia. Aquí se aplica directamente la regulación establecida por el derecho europeo, con independencia de que esté establecida en una directiva o en un reglamento. Esa normativa agota el espacio regulador. El informe de evaluación (y el consenso sobre el mismo) se proyecta sobre dos elementos. De una parte, la inexistencia de riesgos para la salud. De otra parte, la inexistencia de afección a derechos de protección de datos de un titular de una autorización de comercialización previa. Cualquier Estado miembro puede rechazar la aprobación del informe de evaluación del medicamento genérico si considera que el plazo de protección de datos no ha expirado. Pero si el informe es aprobado por todos los Estados afectados, ningún Estado miembro puede posteriormente examinar y determinar unilateralmente tanto el riesgo para la salud como si el plazo de protección de datos había expirado. Desde el momento de la aprobación del informe de evaluación, todos ellos están obligados a otorgar la autorización de comercialización ${ }^{34}$.

En los procedimientos descentralizado y de reconocimiento mutuo, configurados como procedimientos compuestos horizontales, la existencia de

34 Sentencia del Tribunal de Justicia de 23 de octubre de 2014, Olainfarm, C-104/13, EU:C:2014:2316. 
desacuerdo sobre la evaluación científica al considerar alguno de los Estados miembros que existe un riesgo potencial grave para la salud pública de forma motivada, incorpora una nueva fase, el denominado "procedimiento de revisión» (review procedure) ${ }^{35}$. En primer lugar, intentando alcanzar el acuerdo dentro del Grupo de Coordinación para el Reconocimiento Mutuo y los Procedimientos Descentralizados — uso humano- (CMDh) o del Grupo de Coordinación para el Reconocimiento Mutuo y los Procedimientos Descentralizados - uso veterinario- (CMDv). Estos grupos ${ }^{36}$ no adoptan ninguna decisión formalizada otorgando o denegando la autorización, o emitiendo un concreto informe de evaluación (Röttger-Wirtz y Eliantonio, 2019: 400). Son órganos de composición informal, de tal forma que si se logra el consenso (unanimidad), los Estados miembros otorgarán directamente su autorización nacional. Si no se logra el consenso, se establece una nueva fase centralizada en la EMA, donde el Comité de Medicamentos de Uso Humano (CHMP) o el Comité de Medicamentos de Uso Veterinario (CVMP) elabora un dictamen sobre la evaluación científica, y sobre el cuál la Comisión adopta una decisión conforme al procedimiento de examen (mayoría cualificada) ${ }^{37}$, por la que se concede, modifica, deniega o revoca la autorización de comercialización. El informe científico de la EMA puede asumir o rechazar el informe realizado inicialmente por el Estado de referencia, y debe resolver las discrepancias observadas en el grupo de coordinación. El acto de ejecución de la Comisión es comunicado a todos los Estados miembros que participan en el procedimiento y al solicitante. Los Estados miembros deben conceder o denegar la autorización de comercialización o introducir en la misma las modificaciones que sean necesarias para ajustarse a la decisión de la Comisión, informando a la misma y la Agencia Europea ${ }^{38}$. Se articula así un procedimiento compuesto donde el papel de la EMA y la Comisión resuelven los desacuerdos entre los

35 Este no es un procedimiento de arbitraje, de utilización voluntaria, sino un procedimiento autónomo y obligatorio donde resuelve una única instancia, la Comisión Europea, ante la falta de acuerdo de los Estados miembros. Se trata, por tanto, de un procedimiento compuesto triangular, Alonso de León (2017: 159).

36 Estos grupos están compuestos por un representante por cada Estado miembro (más Noruega, Islandia y Liechtenstein), nombrado por un período renovable de tres años. En sus reuniones también participan observadores de la Comisión Europea y de los países candidatos a la adhesión a la UE. La EMA asume la secretaría de cada uno de ellos.

37 Art. 5 Reglamento (UE) 182/2011.

38 Conforme a los arts. 32-33 Directiva 2001/83/CE para los medicamentos de uso humano. Para los medicamentos de uso veterinario, cfr. art. 54 Reglamento (UE) $2019 / 6$. 
Estados miembros ${ }^{39}$. Las decisiones de los Estados miembros se adoptan ahora sin ningún margen de apreciación ${ }^{40}$.

En definitiva, se persigue lograr una decisión valorativa que pueda sea compartida por el mayor número de Estados miembros, evitando un ulterior recurso ante el TJUE por vulneración de la libertad de circulación de mercancías (De Lucia, 2016: 102). Si el consenso no se logra, la decisión final es adoptada por la Comisión, que realiza la valoración con efectos vinculantes frente a todos los Estados miembros, al adoptarse una autorización centralizada. Dado el limitado número de ocasiones en los que resulta necesaria esta forma de resolución de conflictos, donde se produce una composición de los intereses de los distintos Estados miembros en principio sobre bases exclusivamente científicas, el grado de incertidumbre ${ }^{41}$ para los operadores privados queda sustancialmente reducido.

Tanto los procedimientos descentralizados como los de reconocimiento mutuo responden a la necesidad de evitar cargas administrativas y financieras innecesarias para los solicitantes y las autoridades competentes. La participación de los Estados que reciben una solicitud de reconocimiento mutuo o de evaluación en un proceso descentralizado se articula sobre la atribución de un margen de apreciación limitado, fijando los supuestos fácticos que permiten a un Estado miembro denegar el reconocimiento de la autorización de comercialización. Salvo cuando exista un riesgo para la salud pública, la evaluación del reconocimiento debe basarse en las consideraciones y las evaluaciones científicas realizadas por el Estado miembro de referencia ${ }^{42}$. Evaluaciones que, desde la perspectiva de su control judicial, gozan de una amplia deferencia ${ }^{43}$. Aún cuando el derecho secundario no lo impone, la configuración de la evaluación científica como el elemento clave en el proceso de otorgamiento de la autorización de comercialización de los medicamentos, así como la exigencia de una clara imparcialidad de las autoridades y de los expertos que las integran y de un funcionamiento en red, han conducido a los Estados miembros a atribuir generalmente la competencia a agencias o autori-

39 En la doctrina se encuentran referencias imprecisas a una mediación o arbitraje. P. ej, Brito Bastos (2018:107).

40 Prácticamente se produce una ratificación de la decisión de la Comisión. Sobre ello, Brito Bastos (ibid.:108).

41 Incertidumbre denunciada por De Lucia (2016: 102).

42 Sentencia del Tribunal de Justicia de 16 de octubre de 2008, Synthon, C-452/06, EU:C:2008:565.

43 P.e., Raad van State (Consejo de Estado) de Holanda de 10 de octubre de 2018, NL:RVS:2018:3298; Raad van State (Consejo de Estado) de Holanda de 25 de abril de 2018, NL:RVS:2018:1354. 
dades independientes. Tales agencias son las que participan en la construcción de la evaluación científica o asumen el efectuado por otra agencia, y son las autoridades competentes para otorgar la autorización.

\section{LA EFECTIVA UTILIZACIÓN DE LOS DISTINTOS PROCEDIMIENTOS. PREPONDERANCIA DEL PROCEDIMIENTO DESCENTRALIZADO}

Los datos estadísticos de la utilización de estos procedimientos en el mercado interior ofrecen resultados significativos. Las autorizaciones nacionales de comercialización, aunque posibles, presentan hoy un alcance muy limitado, dado que solo permiten la comercialización dentro del territorio del único Estado miembro que la haya otorgado (Röttger-Wirtz y Eliantonio, 2019: 393). En términos de volumen, las autorizaciones de comercialización obtenidas a través de un procedimiento descentralizado o a través de la figura del reconocimiento mutuo superan a las autorizaciones obtenidas mediante el procedimiento centralizado (Ebbers et al., 2015: 1238; Langedijk et al., 2016: 47). Si bien hasta 2007 el mayor número de procedimientos de autorización se articulan a través del procedimiento de reconocimiento mutuo, desde 2008 el procedimiento de autorización descentralizada adquiere una preponderancia incontestable ${ }^{44}$, dado que es el que debe seguirse cuando no existe una autorización previa. La adopción de un enfoque descentralizado del mercado interior en el sector del medicamento supone no solo una opción económica en términos de organización de las estructuras administrativas, sino también un enfoque que preserva la capacidad de decisión de los Estados miembros (Hofmann, 2019: 3).

Paralelamente, se observa un significativo descenso en el recurso a la intervención del Grupo de Coordinación de Reconocimiento Mutuo y Procedimientos Descentralizados —uso humano- $(\mathrm{CDMH})$ desde los primeros años, al presentar una mayor incidencia en los procedimientos de reconocimiento mutuo que en los procedimientos descentralizados ${ }^{45}$. La razón de este

44 Así, p.ej., en 2013 se tramitaron 1052 procedimientos descentralizados frente a 207 procedimientos de reconocimiento mutuo, y solo 80 procedimientos centralizados. En 2018 se han tramitado 1023 procedimientos descentralizados frente a 291 procedimientos de reconocimiento mutuo y 84 procedimientos centralizados.

45 Ebbers et al. (2015: 1239), que lo cuantifican en cinco veces. La razón se encuentra, entre otros factores, en que en el procedimiento descentralizado no existe una previa autorización de comercialización otorgada, por lo que el solicitante puede retirar su solicitud con mayor facilidad en respuesta a las objeciones formuladas durante el procedimiento de evaluación, con el fin de volver a presentar su solicitud con nuevos elementos o en diferentes Estados miembros. 
descenso se encuentra en una mayor interiorización de la necesidad de los Estados miembros en buscar consensos en las fases previas del procedimiento de autorización, a lo que ha coadyuvado la elaboración de orientaciones precisas por el CMDH sobre lo que se consideran riesgos potenciales graves para la salud pública. Las mismas han reducido los desacuerdos entre los distintos Estados miembros, a la par que han permitido un «aprendizaje regulatorio» de los solicitantes (Ebbers et al., 2015: 1241). Estas monografias, elaboradas por los diferentes comités científicos integrados en la EMA, incorporan las evidencias científicas e históricas relativas a los aspectos de calidad, seguridad y eficacia ${ }^{46}$, dentro de los parámetros fijados por las guías adoptadas por el Consejo Internacional para la Armonización de los Requisitos Técnicos para el Registro de Productos Farmacéuticos para Uso Humano (ICH) (Mendes, 2014: 375) ${ }^{47}$. Las monografías (Vaughan, 2015: 71) ${ }^{48}$ son utilizadas como el material de referencia que fija los estándares de seguridad y eficacia, y son asumidas tanto por los operadores que formulan la solicitud como por las autoridades nacionales, tanto la del Estado de referencia como la de los Estados concernidos (Qu et al., 2018: 220). La adopción de estas monografías se articula a través de un procedimiento de consulta donde el peso de la industria farmacéutica queda equilibrado por la incorporación de representantes de pacientes, consumidores y profesionales de la salud en sus procedimientos de consulta. En ambos casos, cuando se recurre al Comité se obtiene un consenso cercano al

46 En la elaboración de las monografías, el respectivo comité evalúa toda la información disponible, incluidos los datos clínicos y no clínicos, el uso y la experiencia suficientemente en el ámbito de la Unión Europea y, si se dispone de ellos, también de los datos obtenidos fuera del territorio europeo siguiendo un procedimiento de trabajo normalizado.

47 Las guías del ICH se adoptan a través de un procedimiento donde la fase de consulta no garantiza la debida consideración de las opiniones expresadas, ya que el grupo de trabajo de expertos del ICH no revela la justificación para aceptar o rechazar los comentarios recibidos, frente a los procedimientos seguidos por la EMA, donde ese estándar procedimental sí queda garantizado formalmente. Es más, en dicho procedimiento de la ICH no se garantiza necesariamente la protección del interés de los usuarios, ya que su función de armonización técnica a nivel mundial está guiada por intereses comerciales. No obstante, la autoridad de las guías de la ICH tiene su fundamento en que son adoptadas por foro internacional de expertos, compuesto por reguladores y la industria, que las configura como mejores prácticas posibles.

48 Estas guías adoptadas por las agencias europeas funcionan como mecanismo correctivo de los defectos, lagunas u omisiones del derecho secundario, y gozan de una amplia discreción en la interpretación y aplicación de ese derecho secundario, lo que permite calificarlas como normas híbridas. 
$70 \%$ y se deniegan las autorizaciones en un porcentaje relativamente bajo ${ }^{49}$ -frente a las denegaciones en el procedimiento centralizado, que alcanzan hasta una cuarta parte de las presentadas (Langedijk et al., 2016: 47), si bien igualmente se está produciendo una disminución significativa de las denegaciones- ${ }^{50}$.

\section{PROCEDIMIENTO DESCENTRALIZADO Y SISTEMAS DE RECURSOS (ADMINISTRATIVOS Y JUDICIALES) DE LOS ESTADOS MIEMBROS. LA PROYECCIÓN DEL DERECHO EUROPEO SOBRE EL SISTEMA DE TUTELA JUDICIAL NACIONAL}

La atribución descentralizada de funciones en el plano administrativo (unión administrativa) tiene como reflejo igualmente una atribución descentralizada de competencias de control judicial de la actuación administrativa (unión administrativa y judicial). La práctica demuestra cómo las autoridades administrativas y las judiciales de los diferentes Estados miembros comparan y alinean sus posiciones. El procedimiento administrativo descentralizado de autorización de comercialización de medicamentos da lugar a un procedimiento compuesto multijurisdiccional en tanto que las distintas autorizaciones son adoptadas a través de un procedimiento donde han intervenido las autoridades administrativas de los distintos Estados miembros, siendo controlables a tenor de su respectiva normativa jurisdiccional por sus tribunales nacionales (Hofmann, 2019: 2). El análisis que se realiza a continuación permite determinar si el principio de Estado de derecho se respeta, tanto en su dimensión objetiva (el efectivo sometimiento de los poderes públicos, nacional y europeo, a la ley) como en su dimensión subjetiva (la posibilidad de los interesados para reaccionar frente a los excesos del poder público). Los problemas de tutela judicial de los interesados deben resolverse a la luz del principio de exclusividad de la jurisdicción nacional para revisar la legalidad de las medidas administrativas nacionales, pero también a la luz

49 Y aquí las objeciones del PSRPH que se relacionaban con el diseño de los estudios clínicos y la demostración de la equivalencia terapéutica y la bioequivalencia son las causas más comunes que conducen a la denegación de la autorización, mientras que las controversias sobre la calidad o sobre el cumplimiento de los requisitos normativos solo en limitadas ocasiones conducen a la denegación de la autorización.

50 En 2018, solo se han denegado cinco solicitudes, conforme al Informe Anual de EMA, disponible en: https://bit.ly/3mYzEgU. 
de los principios de autonomía y uniformidad del sistema jurídico europeo respecto de los sistemas jurídicos nacionales.

En el procedimiento de autorización de comercialización, el procedimiento descentralizado horizontal implica, en la medida en que el elemento clave es la evaluación científica del riesgo, que ésta es realizada de forma compartida por los distintos Estados miembros. Esa evaluación, si bien realizada bajo la dirección del Estado de referencia que realiza la evaluación inicial, supone un intercambio activo de información entre los distintos Estados, que emiten sus alegaciones, asumiendo o enmendando, la valoración previa. ¿Es posible el control jurisdiccional por los órganos de los Estados concernidos sobre la valoración incorporada por sus órganos administrativos en el procedimiento compuesto horizontal que adopta la primera decisión sobre la autorización de comercialización o sobre la propia valoración del Estado de referencia? Las claves normativas para articular una respuesta a tal interrogante son las siguientes. En primer lugar, los reglamentos europeos que regulan la autorización de comercialización no han previsto una posible «remisión prejudicial horizontal» (horizontal preliminary reference) que permita una revisión preliminar por parte de un órgano jurisdiccional de otro Estado miembro (Hofmann, 2019: 19; Röttger-Wirtz y Eliantonio, 2019: 404). Aún cuando se ha propugnado que una interpretación conforme al derecho a la tutela judicial efectiva ${ }^{51}$ en clave europea posibilita que la decisión administrativa nacional en procedimientos compuestos multijurisdiccionales horizontales pueda ser revisada por la Administración de otro Estado miembro y sus órganos judiciales (Hofmann, 2019: 21), lo cierto es que las autoridades nacionales de los Estados concernidos no pueden cuestionar de forma unilateral la validez y efectividad de la autorización otorgada por el Estado de referencia o por cualquier otro Estado concernido ${ }^{52}$. Y ello porque su participación en el procedimiento de autorización permite garantizar adecuada y tempestivamente los intereses del Estado concernido (dimensión procedimental de la vinculación interadministrativa) (De Lucia, 2016: 100).

51 En los términos fijados por la Sentencia del Tribunal de Justicia de 9 de febrero de 2017, Staatssecretaris van Financiën, C-283/15, EU:C:2017:102, relativa a un procedimientos de cooperación horizontal en materia impositiva, donde se afirma que los órganos jurisdiccionales del Estado miembro que recibe una solicitud de información puedan controlar la legalidad de tal solicitud de información, verificando si la información solicitada por el Estado miembro requirente «no carece de toda relevancia previsible para la investigación que está llevando a cabo la autoridad requirente».

52 Sentencia del Tribunal de Justicia de 14 de marzo de 2018, Astellas Pharma, C-557/16, EU:C:2018:181; y Sentencia del Tribunal de Justicia de 23 de octubre de 2014, Olainfarm, C-104/13, EU:C:2014:2316. 
En segundo lugar, debe identificarse a los posibles sujetos que ostentarían ese derecho a la tutela judicial efectiva a la luz de los intereses protegidos por la norma. Y, finalmente y en tercer lugar, debe identificarse el ámbito de responsabilidad de cada Administración nacional dentro del procedimiento administrativo compuesto horizontal.

\section{TUTELA DE USUARIOS O TERCEROS IMPARCIALES EN LA FASE ADMINISTRATIVA DE OTORGAMIENTO DE LA AUTORIZACIÓN}

Como se ha señalado, los procedimientos de autorización de comercialización se configuran como procedimientos bilaterales donde la Administración competente debe tomar en cuenta el interés del solicitante de la autorización de comercialización y el interés público relativo a la protección de la salud de las personas. La tutela de los intereses de los ciudadanos se asume directamente por la Administración que participa en el procedimiento. Esa configuración determina que no se prevea la apertura de un trámite de información pública o de alegaciones de terceros. ¿Implica esta opción reguladora que no puede cualquier tercero participar en dicho procedimiento en concepto de interesado ni erigirse en interlocutor de las Administraciones competentes en el marco de la evaluación de datos científicos acerca del medicamento en cuestión? ¿Existe aquí un déficit del derecho a la tutela judicial o más bien del principio de buena administración?

El examen de esta cuestión requiere ampliar el foco de análisis. En el procedimiento de elaboración de los estándares regulatorios internacionales (guías de ICH), que posteriormente son recepcionadas por las monografías (guidelines) de EMA, existe un evidente déficit, puesto que la participación de los ciudadanos o de las pequeñas empresas farmacéuticas es prácticamente inexistente (Mendes, 2014: 378). En el procedimiento de adopción de las guías de ICH no existen garantías (formalizadas) procedimentales de tutela de los derechos o intereses de los ciudadanos. Las reglas procedimentales para adoptar posteriormente las monografías de la EMA son también débiles (Vaughan, 2015: 75) ${ }^{53}$. Siendo regulaciones materialmente vinculantes (donde solo se permite apartarse de las mismas de forma justificada) su procedimiento de adopción es opaco (Vaughan, 2015: 85). No garantizan suficientemente la posible retroalimentación que debe darse a los participantes ni la justificación de las opciones finalmente establecidas. Debilidad que compromete la

53 EMA no tiene atribuida de forma expresa la competencia para adoptar estas guías, por lo que actúa con una gran discreción respecto a qué, cuándo y cómo las implementa. 
capacidad del procedimiento para estructurar la racionalidad y corrección de la decisión adoptada (Mendes, 2014: 390) ${ }^{54}$.

La regulación de los concretos procedimientos de otorgamiento de autorización de comercialización (centralizado, reconocimiento mutuo o descentralizado) tampoco incorpora reglas efectivas de participación de terceros (usuarios o terceros imparciales). La falta de una previsión específica de participación en el derecho secundario no impide que cualquier sujeto, sea a título individual o sea una organización de defensa de los intereses de pacientes, pueda hacer llegar sus observaciones científicas al órgano competente, quien necesariamente debe tenerlas en cuenta en la concreción de su valoración científica como justificación de su decisión (principio de buena administración). Pero esa aportación no lo convierte en interesado en el procedimiento de autorización, ni permite considerarlo — prima facie — legitimado para impugnar ulteriormente la concreta decisión (Olivieri) $)^{55}$. El argumento de la especial complejidad técnica no resulta admisible. Se produce así una aplicación restrictiva del derecho de audiencia (art. 41 CDFUE), que se suma a la interpretación restrictiva de la legitimación activa ante el TJUE ex art. 263 TFUE. Y esa limitación del derecho de audiencia no resulta compensada por el reconocimiento de un derecho de acceso a la información a través de las normas europeas o nacionales de trasparencia una vez otorgada la autorización de comercialización (MSD Animal Health Innovation) ${ }^{56}$.

54 La interdependencia funcional de las opciones regulatorias adoptadas a nivel internacional o transnacional y a nivel de la UE. Ello conduce a buscar los vínculos externos de los procedimientos de toma de decisiones, configurados como procedimientos compuestos. Pero en todo caso, la EMA debe justificar que las decisiones adoptadas externamente en el ICH no contradicen el contenido del derecho europeo. Sentencia del Tribunal General de 18 de diciembre de 2003, Olivieri/Comisión y EMEA, T-326/99, EU:T:2003:351, donde las alegaciones son aportadas por una científica experta mundialmente reconocida. En el ámbito de las autorizaciones centralizadas solo se reconoce legitimación al tercero si es afectado por una decisión de la Comisión que se le hubiera dirigido y por la que se hubiera denegado el examen de la información que haya remitido en el procedimiento de evaluación científica o por una decisión desestimatoria presunta en el caso de que la Comisión haya otorgado la autorización de comercialización sin haber examinado su información.

Sentencia del Tribunal General de 5 de febrero de 2018, MSD Animal Health Innovation y Intervet international/EMA, T-729/15, EU:T:2018:67, donde se precisa que no existe una presunción de confidencialidad de los datos contenidos en los estudios de evaluación científica, salvo los relativos a la información comercial confidencial, de interpretación restrictiva. 
La tutela de los ciudadanos que puedan verse afectos por las autorizaciones de comercialización, en cuanto usuarios de los medicamentos que sufran daños por su utilización, queda constreñida a la ulterior constatación y cuantificación de tales daños. La controversia jurídica suscitada ante el órgano judicial nacional solo puede focalizar su análisis sobre el comportamiento de la empresa autorizada que genera el daño, pero no podrá tomarse como objeto de análisis jurisdiccional la autorización otorgada por el Estado de referencia o por su Estado en cuanto Estado concernido (De Lucia, 2016: 103).

\section{LA ATRIBUCIÓN DE LEGITIMACIÓN A LOS TERCEROS COMPETIDORES. ¿̇EFECTOS TRANSNACIONALES O ATRIBUCIÓN FUNCIONAL DE RESPONSABILIDADES? LA GARANTÍA DEL PRINCIPIO DE UNIFORMIDAD Y EL CONTROL JUDICIAL DESCENTRALIZADO}

Ciertamente el derecho secundario reconoce al titular de una previa autorización de comercialización de un medicamento varios derechos que se proyectan fuera de la relación jurídico-administrativa trabada con la Administración de referencia, vinculados a la protección de datos y la exclusividad comercial en ulteriores procedimientos de autorización de medicamentos genéricos. La protección del operador económico que obtiene una autorización se articula confiriéndole, por un periodo de ocho años a partir de la autorización inicial del producto de referencia, un derecho de protección de la «exclusividad de datos» ${ }^{57}$. Transcurrido ese periodo, cualquier tercero podrá presentar solicitudes válidas para productos genéricos y dar lugar a la concesión de una autorización de comercialización (a través del procedimiento descentralizado). Las solicitudes de medicamentos genéricos solo pueden presentarse transcurridos diez años desde el otorgamiento de la autorización del medicamento de referencia. Ese plazo se computa a partir de la autorización inicial del producto de referencia ${ }^{58}$, que proporciona un derecho de "protección

57 Por datos debe entenderse las pruebas, los estudios preclínicos y los ensayos clínicos. Elementos que representan para las empresas una inversión importante y necesaria para obtener la autorización de comercialización. Los mismos se protegen para estimular la investigación y la innovación, frente a su uso por otros solicitantes de forma limitada en el tiempo, con el fin permitir la competencia y evitar la repetición innecesaria de pruebas cuyos resultados ya están testados.

58 El período de protección de archivos y la exclusividad del mercado se calcula con la fecha de inicio en el momento en que se otorgó la primera autorización en la Unión Europea. Todos los medicamentos que pertenecen a la misma autorización de comercialización global (GMA) tienen la misma fecha de inicio. El GMA comprende la primera autorización de un medicamento y todas sus variaciones y extensiones 
del mercado», después del cual los productos genéricos autorizados de esta manera pueden comercializarse.

Desde esa premisa, el derecho secundario reconoce al titular de una autorización de comercialización, de una parte, el derecho a exigir que el medicamente para el que obtuvo una autorización no sea utilizado como medicamento de referencia en el procedimiento de autorización de comercialización de un medicamento genérico de otro fabricante antes de la finalización del plazo de exclusividad. $\mathrm{O}$ que un medicamento que haya obtenido la autorización no se comercialice antes de la finalización del plazo de precaución desde su autorización. De otra parte, se le reconoce el derecho a exigir que el medicamento para el que obtuvo autorización no sea utilizado para la obtención por un tercero de otra autorización de comercialización de un nuevo medicamento genérico respecto al cual su propio medicamento no pueda ser considerado medicamento de referencia. Es así, directamente, el derecho de la Unión Europea el que le reconoce legitimación para cuestionar ante los órganos administrativos y jurisdiccionales de los Estados miembros que tramitan un procedimiento descentralizado que su producto pueda ser utilizado como medicamento de referencia y puedan utilizarse los datos obtenidos en relación con dicho producto para conceder una autorización de comercialización de un producto genérico (Olainfarm) ${ }^{59}$. El art. 47 de la Carta de los Derechos Fundamentales de la Unión Europea obliga a que se le reconozca el derecho a la tutela judicial para la defensa de esos derechos durante el plazo de protección. Es directamente el derecho europeo el que otorga esa tutela, desplazando, en su caso, a la normativa procesal nacional. Pero esa tutela debe impetrarla en cada uno de los Estados miembros que han otorgado la autorización de comercialización, de conformidad con las normas de procedimiento nacional pertinentes, incluidos los plazos aplicables para interponer tal recurso. Se fragmenta así su derecho a la tutela judicial, sin que el órgano jurisdiccional de un Estado miembro pueda cuestionarse la compatibilidad con el derecho de la Unión de las autorizaciones de comercialización concedidas por las autoridades competentes de otro Estado miembro

en términos de concentraciones, formas farmacéuticas, métodos de administración y formas de presentación. La GMA no incorpora un acto formal, sino que implica una noción interpretativa.

59 Sentencia del Tribunal de Justicia de 23 de octubre de 2014, Olainfarm, C-104/13, EU:C:2014:2316. Este reconocimiento está asumido implícitamente, también, en la Sentencia del Tribunal de Justicia de 14 de febrero de 2019, Staat der Nederlanden/ Warner-Lambert Company LLC, C-423/17, EU:C:2019:125. 
$(\text { Astellas Pharma })^{60}$. Y esa legitimación la ostenta no solo en la vía judicial, sino también en la vía administrativa, para cuestionar en el procedimiento descentralizado la solicitud presentada (primacía del derecho europeo) ${ }^{61}$.

En la arquitectura de la unión administrativa, el reconocimiento de este ámbito de tutela para el titular de la primigenia autorización de comercialización debe proyectarse sobre el derecho nacional, posibilitando una ampliación del alcance del derecho a la tutela judicial efectiva reconocido por la normativa de cada Estado miembro, no una restricción de dicha protección ${ }^{62}$. En efecto, concluido el período de protección (de su exclusividad temporal), la legitimación para recurrir una autorización de comercialización concedida a un tercero no deriva ya del reconocimiento de derecho subjetivo alguno, sino que entronca entonces con el reconocimiento de la existencia de un posible interés legítimo en cuanto competidor que opera en el mismo segmento de mercado y en la misma zona de actividad. Aquí el derecho secundario ya no protege ningún interés propio del recurrente, lo que se proyecta sobre el alcance material del control judicial que pueda impetrarse ante los órganos judiciales de un Estado miembro. El derecho secundario de la Unión Europea no incorpora directamente ninguna regulación relativa a la protección de los derechos del titular de una autorización de comercialización una vez transcurrido el periodo de protección de sus derechos de comercialización cuya sustancia activa es utilizada en la posterior solicitud de una autorización de comercialización para un medicamento genérico a través del procedimiento descentralizado.

60 Sentencias del Tribunal de Justicia de 14 de marzo de 2018, Astellas Pharma, C-557/16, EU:C:2018:181, y de 23 de octubre de 2014, Olainfarm, C-104/13, EU:C:2014:2316. Expresamente, el Tribunal de Justicia afirma que «el imperativo de tutela judicial efectiva no supone que el titular de la AC del medicamento de referencia pueda impugnar ante ese mismo órgano judicial la conformidad con la Directiva 2001/83 de las decisiones de AC del medicamento que hayan adoptado otros Estados miembros, puesto que el derecho de ese titular a recurrir contra esas otras decisiones podrá ejercitarse, o podría haberse ejercitado dentro de los plazos disponibles, ante los órganos jurisdiccionales a los que corresponda el control de legalidad de las decisiones adoptadas por las autoridades nacionales competentes en cada Estado miembro». Este criterio ha sido expresamente asumido por la decisión de la High Court of Justice (Queen's Bench Division. Administrative Court) de 21 de marzo de 2019 (CO/471/2018. [2019] EWHC 689 (Admin).

61 Sentencia del Juzgado Central de lo Contencioso-Administrativo de 2 de julio de 2018, ES:AN:2018:4252, que rectifica su posición anterior.

62 Raad van State (Consejo de Estado) de Holanda de 10 de octubre de 2018, NL:RVS:2018:3298. 
En esta tesitura, el principio de autonomía procesal nacional es interpretado por los órganos jurisdiccionales nacionales en los siguientes términos. Las normas procesales aplicables a la evaluación judicial de las acciones de protección de los derechos que los particulares derivan del derecho de la Unión Europea se rigen, en principio, por el derecho nacional, siempre que dichas normas procesales respeten los principios de equivalencia, eficacia y tutela judicial efectiva. El órgano jurisdiccional debe analizar, en primer lugar, y sobre la base de las normas procesales nacionales, si el recurrente ostenta legitimación. Solo si a la luz de las normas procesales nacionales el recurrente no ostenta prima facie legitimación, el órgano jurisdiccional debe cuestionarse si las normas nacionales respetan los principios de equivalencia, efectividad y protección legal efectiva, en la medida en que el recurrente pueda derivar derechos de la normativa de la Unión invocada ${ }^{63}$.

A pesar de la ausencia de una regulación procedimental detallada en el derecho secundario, se puede considerar a un competidor, cuyo interés competitivo se vea directamente afectado por una resolución, como parte interesada en el procedimiento descentralizado de autorización de medicamentos. Ese concepto de interés legítimo requiere concretarse. Solo se estará legitimado si el tercero es un operador que actúa en el mismo segmento de mercado y en la misma zona de actividad (requisitos cumulativos). Esta noción de interés legítimo puede adoptarse con independencia del alcance efectivo que pueda desempeñar el interés competitivo en la adopción de la resolución que ponga fin al procedimiento descentralizado ${ }^{64}$. Si la solicitud de comercialización se presenta sobre la base de un principio activo ya existente, pero para tratar una enfermedad distinta, el titular de una autorización de comercialización sobre el mismo principio activo, pero que sirve de base a un medicamento para otra enfermedad, no estará legitimado para cuestionar el otorgamiento o la denegación de la autorización. Igualmente, tampoco ostentará legitimación aquella empresa que tenga una autorización de comercialización para comercializar en un país distinto del que ahora se solicita la autorización.

$\mathrm{El}$ interés de ese tercer competidor le permite, dentro del procedimiento de autorización descentralizado, cuestionar ante los órganos jurisdiccionales

63 Raad van State (Consejo de Estado) de Holanda de 10 de octubre de 2018, NL:RVS:2018:3298.

64 Esta es, p.ej., la posición adoptada por el Raad van State (Consejo de Estado) de Holanda de 25 de abril de 2018, NL:RVS:2018:1354. La percepción del ejercicio de acciones judiciales del tercer competidor en defensa del interés público, en cuanto guardianes que litigan contra un producto presuntamente inseguro, queda diluido en la defensa de sus intereses comerciales 
del Estado de referencia la decisión sobre cuál es el procedimiento que debe tramitarse $^{65}$ : si debe tramitarse mediante una solicitud ordinaria (que requiere aportar los resultados de los ensayos preclínicos y clínicos, lo que implica una inversión considerable) ${ }^{66}$; o mediante una solicitud abreviada (donde ante la existencia de una equivalencia biológica, basta con aportar los estudios realizados para obtener la autorización de comercialización del medicamento de referencia, lo que determina una menor inversión) ${ }^{67}$; o mediante una solicitud híbrida (donde se debe demostrar la equivalencia terapéutica a través de la realización de ensayos preclínicos y clínicos adicionales y si, por lo tanto, está justificado hacer referencia al expediente del medicamento de referencia ${ }^{68}$. Solo cabrá cuestionar esta decisión cuando se solicite una autorización para un nuevo principio activo, no para un medicamento genérico ${ }^{69}$. Igualmente, ese interés le permite cuestionar la apreciación de la expiración de su derecho de exclusividad dentro del procedimiento de autorización. No hay margen de apreciación en la determinación del periodo de exclusividad. Una vez concluida la valoración en el procedimiento seguido ante el Estado de referencia, el resto de autoridades de los Estados concernidos no pueden cuestionar nuevamente el vencimiento del período de protección de datos del medicamento de referencia (Astellas Pharma) ${ }^{70}$.

65 Raad van State (Consejo de Estado) de Holanda de 10 de octubre de 2018, NL:RVS:2018:3298.

66 Art. 8 Directiva 2001/83/CE para los medicamentos de uso humano, y art. 8 Reglamento (UE) 2019/6 para medicamentos de uso veterinario.

67 Art. 10 Directiva 2001/83/CE para los medicamentos de uso humano y art. 18 Reglamento (UE) 2019/6 para medicamentos de uso veterinario.

68 Art. 10 bis Directiva 2001/83/CE para los medicamentos de uso humano y art. 19 Reglamento (UE) 2019/6 para medicamentos de uso veterinario.

69 Como precisa la Sentencia del Raad van State (Consejo de Estado) de Holanda de 10 de octubre de 2018, NL:RVS:2018:3298, no puede exigirse por el titular de la primera autorización que la solicitud de un medicamento genérico deba verificarse mediante el uso del procedimiento completo, que requiere una gran inversión de tiempo y dinero. Y ello porque tal circunstancia supondría en la práctica que el titular de la primigenia autorización conservase la exclusividad del mercado. Esta interpretación resulta inconsistente con los objetivos perseguidos por la regulación europea de que el desarrollo de la industria farmacéutica y el comercio de los medicamentos no se limiten innecesariamente. Además, la protección de la salud rechaza las pruebas repetidas de humanos y animales. Por tanto, debe optarse por la interpretación que simplifique el acceso al mercado comunitario de medicamentos genéricos.

70 Sentencia del Tribunal de Justicia de 14 de marzo de 2018, Astellas Pharma, C-557/16, EU:C:2018:181. 
¿Cómo articular la eficacia de la actuación realizada a través del procedimiento descentralizado de autorizaciones de comercialización y el régimen de recursos, en vía administrativa y contencioso-administrativa, establecidos por las legislaciones de los Estados miembros? Aquí debe efectuarse una interpretación de los recursos que no desnaturalice la naturaleza del sistema colaborativo que implica la unión administrativa ${ }^{71}$. En primer lugar, ¿pueden esos órganos jurisdiccionales de un Estado revisar el análisis científico emitido por su Administración competente en cuanto Estado de referencia o Estado concernido o el emitido por la Administración de otro Estado miembro, en cuanto Estado de referencia o Estado concernido? La respuesta debe ser negativa cuando tal evaluación científica sea objeto de cuestionamiento autónomo, con carácter previo al otorgamiento de la autorización, ya que la misma se configura como un acto de trámite (preparatory act) (Röttger-Wirtz y Eliantonio, 2019: 404) que las legislaciones nacionales excluyen, con carácter general $^{72}$, del objeto del control jurisdiccional. Y ello con independencia de que la evaluación científica haya sido adoptada conjuntamente por los Estados afectados primariamente en el procedimiento compuesto o haya sido adoptada ulteriormente, y tras un desacuerdo previo, en el correspondiente grupo de coordinación para el reconocimiento mutuo y los procedimientos descentralizados ${ }^{73}$. Las posibles ilegalidades de la evaluación científica deben ser objeto de cuestionamiento cuando se impugne la autorización (RöttgerWirtz y Eliantonio, 2019: 407), ya que el informe de evaluación adoptado por el órgano competente y los documentos preparatorios del mismo forman parte

71 Sentencia del Juzgado Central de lo Contencioso-Administrativo de 2 de julio de 2018, ES:AN:2018:4252.

72 Debe precisarse que en algún ordenamiento nacional se permite la impugnación autónoma de esos actos de trámite, lo que impediría apreciar la existencia de un déficit de protección derivada del principio de doble exclusividad.

73 No obstante, Röttger-Wirtz y Eliantonio (2019: 404), plantean la posibilidad de un control de la decisión informal allí alcanzada por parte del Tribunal de Justicia, a través de una cuestión preliminar de validez con arreglo al art. 267 del TFUE planteada por un órgano jurisdiccional nacional, aún cuando concluyen que el acto formal es adoptado por cada Estado afectado. El Tribunal de Justicia ha afirmado su competencia para conocer de las cuestiones prejudiciales relativas a los actos de los órganos que se crean «en aplicación de la legislación de la UE» en la Sentencia del Tribunal de Justicia de 27 de octubre de 2016, James Elliott Construction, C-613/14, EU:C:2016:821. Igualmente plantean estos autores la posibilidad de cuestionar la remisión del procedimiento al grupo de coordinación, si bien concluyen igualmente en su imposibilidad, dado que es un trámite dentro del procedimiento complejo. 
integrante de la motivación de la decisión final ${ }^{74}$. Ilegalidades de la evaluación científica que pueden ser materiales o, simplemente, formales. Tales ilegalidades deben ser analizadas a la luz del derecho a una buena administración, que entre otros extremos exige una actuación imparcial (objetiva y subjetiva $)^{75}$, y donde el incumplimiento de ese deber en cualquier fase se traslada a la siguiente ${ }^{76}$. Se produce así en tal supuesto una ilegalidad derivada (Brito Bastos, 2018: 104) en el procedimiento compuesto.

En segundo lugar, la tutela material de los derechos del operador que ha obtenido la primigenia autorización de comercialización en el seno de un ulterior procedimiento de autorización descentralizada en el que se vea afectado el primer medicamento debe proyectarse, primariamente, ante las autoridades administrativas y judiciales del Estado de referencia. Aun cuando la legislación interna de un Estado miembro (que actúa como Estado de referencia) no prevea la participación del tercer interesado (el sujeto que obtuvo la primigenia autorización), la misma debe considerarse modificada (interpretación conforme) tanto en vía administrativa — en el sentido de reconocer la posibilidad de esa participación y de tener que tomar en cuenta sus alegaciones durante la evaluación de la nueva solicitud- como en vía contencioso-administrativa —en el sentido de reconocérsele legitimación para recurrir y defender sus derechos de exclusividad- ${ }^{77}$. A su vez, en los Estados concernidos la funcionalidad del procedimiento descentralizado excluye que puedan debatirse, tanto en sede administrativa como en sede judicial, las cuestiones materiales referentes a la nueva autorización vinculadas a los derechos de exclusividad del primer sujeto autorizado. Estas solo pueden ser objeto de tutela en el Estado de referencia (Astellas Pharma y Olainfarm) ${ }^{78}$. Tampoco puede en los

74 Sentencia del Tribunal General de 18 de diciembre de 2003, Olivieri/Comisión y EMEA T-326/99, EU:T:2003:351.

75 La imparcialidad subjetiva requiere que ninguno de los integrantes de los órganos que realizan la evaluación científica deba tomar partido ni tener prejuicios personales, mientras que la imparcialidad objetiva requiere que el órgano competente que realiza la evaluación ofrezca garantías suficientes para descartar cualquier duda legítima acerca de un posible prejuicio.

76 Como precisa la Sentencia del Tribunal de Justicia de 27 de marzo de 2019, August Wolff y Remedia/ Commission, C-680/16 P, EU:C:2019:257.

77 Reconoce esta legitimación para cuestionar el respeto del derecho de exclusividad la Sentencia del Rechtbank Midden-Nederland de 8 de marzo 2019, NL:RBMNE:2019:1873.

78 Sentencias del Tribunal de Justicia de 14 de marzo de 2018, Astellas Pharma, C-557/16, EU:C:2018:181, y de 23 de octubre de 2014, Olainfarm, C-104/13, EU:C:2014:2316. Aplicando esta doctrina, la Sentencia del Juzgado Central de lo 
Estados concernidos cuestionarse la evaluación científica aprobada. No puede abrirse un nuevo periodo de valoración donde se altere el reparto de funciones entre los Estados miembros que supone el procedimiento descentralizado. En ese procedimiento, cada Estado concernido ya ha participado activamente en la evaluación científica que, entre otros elementos, también analiza el respeto de los derechos protegidos del titular de la autorización de comercialización del medicamento de referencia. Consecuentemente, esta es una cuestión excluida del debate procesal en los Estados concernidos ${ }^{79}$. Ante los órganos administrativos y judiciales de cada Estado miembro concernido solo puede cuestionarse si el órgano administrativo competente ha ejercido correctamente la competencia atribuida: determinar en el procedimiento descentralizado si la autorización de comercialización del medicamento puede presentar un grave riesgo para la salud pública. Fuera de esos supuestos, la decisión de cada Estado concernido se basa en la evaluación impulsada por el Estado de referencia y aprobada de forma conjunta por todos ellos ${ }^{80}$. Cada autoridad administrativa y cada órgano jurisdiccional de un Estado miembro debe confiar en la corrección y legalidad de las autorizaciones de comercialización concedidas en otros Estados miembros de conformidad con el derecho de la UE. En consecuencia, el derecho a la tutela judicial ex art. 47 CDFUE reconocido al titular de la primigenia autorización de comercialización del medicamento de referencia no faculta para cuestionar ante los órganos jurisdiccionales de un Estado miembro que ha participado en el procedimiento descentralizado las autorizaciones de comercialización del medicamento genérico otorgadas por el resto de Estados que hayan participado en el mismo. Debe recurrir de forma individual cada una de esas autorizaciones de comercialización ante los órganos jurisdiccionales de cada uno de los Estados de conformidad con las normas de procedimiento nacional pertinentes, incluidos los plazos aplicables para interponer tal recurso ${ }^{81}$, limitando el objeto de debate en los términos expuestos.

Contencioso-Administrativo de 2 de julio de 2018, ES:AN:2018:4252, excluye que pueda valorarse si el plazo de exclusividad se ha respetado.

79 Esta es la posición afirmada por la decisión de la High Court of Justice (Queen's Bench Division. Administrative Court) de 21 de marzo de 2019 (CO/471/2018. [2019] EWHC 689 (Admin).

80 Por contra, Röttger-Wirtz y Eliantonio (2019: 404) afirman que en el Estado de referencia tampoco podrá cuestionarse la evaluación científica, al ser un acto de trámite. Ello es correcto sí solo se cuestiona el informe, no si la impugnación se dirige frente a la autorización.

81 High Court of Justice (Queen's Bench Division. Administrative Court) de Reino Unido de 21 de marzo de 2019 (CO/471/2018. [2019] EWHC 689 (Admin). 


\section{LA TUTELA ANTE EL PROCEDIMIENTO DE REVISIÓN}

Cuando las autorizaciones se otorgan sobre la base del procedimiento de revisión, el acto de ejecución adoptado por la Comisión tiene como destinatarios a los Estados miembros afectados. Desde la óptica del tercer competidor o de las asociaciones de usuarios, ¿tal acto puede considerarse como un acto del que sean destinatarios o que les afecte directa e individualmente en los términos exigidos por el art. 263 TFUE? Los destinatarios del acto de ejecución son, directamente, los Estados afectados. El solicitante de la autorización de comercialización del medicamente genérico puede acreditar que se ve afectado por la medida de la misma manera que los Estados miembros en cuanto destinatarios del acto (Röttger-Wirtz y Eliantonio, 2019: 408).

Si la decisión adoptada por la Comisión en el procedimiento de revisión es impugnada a través de un recurso directo ante el TJUE por el solicitante, surgen dos cuestiones. En primer lugar, ¿cabe cuestionar la evaluación científica realizada por EMA, que fundamenta el contenido de la decisión adoptada por la Comisión, aduciendo una posible ilegalidad de la evaluación primigenia realizada por el Estado de referencia y que no ha logrado un consenso entre los Estados concernidos? La respuesta debe ser negativa. El TJUE no puede extender su competencia para apreciar alguna ilegalidad derivada en la previa actuación nacional, ya que la evaluación científica realizada por el Estado miembro ni es un trámite del procedimiento de evaluación realizado por EMA (la falta de acuerdo sobre la evaluación nacional conjunta simplemente permite remitir el procedimiento a un nivel europeo) ni es vinculante y determinante para EMA y para la decisión de la Comisión (Brito Bastos, 2018: 116). La aplicación conjunta de los principios de autonomía y uniformidad del derecho de la Unión determina como resultado la independencia (no sujeción) de la actividad de las autoridades nacional al control del TJUE. Aquí no se produce ninguna restricción a la tutela del recurrente, ya que la actuación de la Comisión, que es independiente de la actuación de los Estados miembros, sí es susceptible de un control autónomo por el TJUE, siendo irrelevantes las posibles irregularidades producidas a nivel nacional ${ }^{82}$.

¿Están legitimados los terceros competidores para recurrir ante el TJUE, demostrando que existe una afectación directa? Evidentemente, podrán cuestionar indirectamente el contenido del acto de ejecución a través de la impugnación del acuerdo nacional que otorga la autorización, solicitando del órgano jurisdiccional nacional que formule una cuestión prejudicial ex art.

82 En los términos fijados por la Sentencia del Tribunal General de 11 de septiembre de 2002, Pfizer Animal Health/Consejo, T-13/99, EU:T:2002:209. 
267 TFUE (Röttger-Wirtz y Eliantonio, 2019: 409), alegando la ilegalidad del otorgamiento de la autorización en cuanto ilegalidad derivada del acto de ejecución europeo, configurado aquí como un «acto preparatorio» (Brito Bastos, 2018: 104).

\section{LA TUTELA DEL SOlICITANTE AL QUE SE LE DESESTIMA UNA AUTORIZACIÓN DE COMERCIALIZACIÓN DE UN MEDICAMENTE GENÉRICO}

El solicitante de una autorización para un medicamente genérico puede ver desestimada su solicitud en el procedimiento descentralizado al considerar la autoridad competente del Estado de referencia que los derechos de exclusividad del titular de la autorización del medicamento de referencia aún están en vigor a la luz de los términos de la autorización conferida por la Comisión Europea conforme al procedimiento centralizado. ¿Puede cuestionarse ante los órganos jurisdiccionales del Estado de referencia la legalidad de esa decisión, al considerar que la decisión de la Comisión Europea al fijar el plazo de tutela de los derechos de exclusividad es incorrecta? ${ }^{23}$.

La respuesta requiere precisar si la decisión de la Comisión Europea puede ser recurrida directamente ante el TJUE por el solicitante de la autorización del medicamento genérico (que no ha sido parte en el procedimiento de autorización centralizada ${ }^{84}$ ) en los términos del art. 263.4 TFUE $^{85}$. En otros términos, ¿̇la autorización centralizada puede ser configurada como un acto reglamentario (regulatory act) que tiene efectos frente a un tercero que

83 Este problema se plantea, fundamentalmente, cuando el titular de la autorización de comercialización del medicamento de referencia solicita y obtiene una nueva autorización para otro medicamento con la misma sustancia activa, pero con una indicación terapéutica diferente. Aquí no hay dos autorizaciones de comercialización que deban disfrutar de períodos de exclusividad de datos distintos. Debe configurarse como una autorización de comercialización global, al ser el mismo titular en ambos casos y utilizar la misma sustancia activa, computándose el periodo de exclusividad desde el momento de otorgamiento de la primera autorización (Sentencia del Tribunal de Justicia de 28 de junio de 2017, Novartis Europharm/Comisión, acumulados C-629/15 P y C-630/15 P, EU:C:2017:498).

84 Tanto el solicitante de la autorización centralizada como los Estados miembros son los destinatarios de la decisión, como precisan Röttger-Wirtz y Eliantonio (2019: 410).

85 Una posición contraria en Röttger-Wirtz y Eliantonio (ibid.: 410), quienes consideran que no se trata ni de una medida de aplicación general ni de un acto reglamentario, siendo improbable, a su juicio, que un competidor pueda probar una afectación individual y directa. 
no es parte en el procedimiento de adopción? ${ }^{26 .}$ La respuesta que ofrecen los órganos jurisdiccionales de los Estados miembros es afirmativa ${ }^{87}$. La decisión de la Comisión es vinculante para todos los Estados miembros, al haber sido adoptada en el procedimiento centralizado. Además, la decisión afecta directamente a los posibles competidores, aunque no hayan sido parte en el procedimiento ni sea destinataria de la misma, ya que no puede acceder a la información científica ni presentar una autorización para un medicamento genérico hasta el momento en que expire el derecho de protección. Consecuentemente, no puede cuestionarse directamente ante el órgano jurisdiccional nacional la posible irregularidad de la decisión adoptada en el proceso centralizado. Sí cabría solicitar del órgano jurisdiccional nacional que plantease una cuestión prejudicial ante el TJUE, aduciendo una ilegalidad derivada (Brito Bastos, 2018: 104) en la denegación de la autorización del medicamento genérico, como consecuencia de la ilegalidad de la autorización otorgada en el procedimiento centralizado.

Dada la capacidad técnica y económica de los operadores en este sector, los mismos pueden impugnar tales elementos de la decisión de la Comisión, bien en el plazo de dos meses desde su publicación en el DOUE (art. 263.6 TFUE), bien solicitando a la EMA la reconsideración del periodo de protección a la luz de nuevas evidencias científicas, e impugnando la decisión correspondiente a través de un recurso directo (art. 265 TFUE). Igualmente, podrían presentar su solicitud de autorización de un medicamente genérico a través no del procedimiento descentralizado, sino del procedimiento centralizado (aquí de utilización opcional) y reaccionar en su caso ante la denegación de la autorización por parte de la Comisión. O bien solicitar la tramitación del procedimiento en interés de la Unión e igualmente reaccionar ante una denegación. Todas estas vías indirectas se presentan como medios efectivos de lograr la tutela judicial efectiva ${ }^{88}$.

86 El concepto acto reglamentario comprende «todos los actos de alcance general». Desde esta perspectiva, una decisión es de alcance general si «se aplica a situaciones determinadas objetivamente y produce efectos jurídicos con respecto a categorías de personas previstas en general y en abstracto».

87 High Court of Justice (Queen's Bench Division. Administrative Court) de 4 de mayo de 2018 (CO/40/2018. [2018] EWHC 1051 (Admin)]; High Court of Justice (Queen's Bench Division. Administrative Court) de 13 de febrero de 2018 (CO/1653/2017. [2018] EWHC 228 (Admin).

88 High Court of Justice (Queen's Bench Division. Administrative Court) de 4 de mayo de 2018 (CO/40/2018. [2018] EWHC 1051 (Admin). 


\section{EL PROCEDIMIENTO DESCENTRALIZADO COMO REFLEJO DE UNA UNIÓN ADMINISTRATIVA MULTINIVEL}

El análisis realizado permite ya fijar las características del procedimiento descentralizado como un tipo diferenciado de ejecución colaborativa en la unión administrativa multinivel. Aquí la regulación material corresponde al derecho europeo, fundamentalmente a través de la categoría del reglamento y de normas de soft law adoptadas por órganos administrativos independientes que funcionan en red bajo la dirección de una agencia europea, por lo que no queda espacio en principio para la regulación nacional, ni material ni procedimental, salvo expresa remisión. El centro de gravedad recae así en el derecho europeo. No existe diversidad material entre los diferentes ordenamientos nacionales (o caso de existir, la misma es de detalle). Este modelo regulativo no puede configurarse como un tipo de ejecución indirecta. Tampoco se trata de un modelo regulativo relacional que articule un supuesto de reconocimiento mutuo, siquiera sea automático (Agudo González, 2019: 249). Por el contrario, es directamente el derecho europeo el que atribuye efectos supranacionales (Chinchilla Peinado, 2015: 153; Izquierdo Carrasco, 2018: 423) a un acto que, por motivos operacionales, es adoptado bajo el liderazgo formal de una Administración nacional y la participación activa de la totalidad (o de un número variable) de las demás Administraciones nacionales. No existe ahora una ejecución del derecho europeo compartimentalizada entre las diferentes Administraciones de los Estados miembros que requiera la adopción de una decisión estándar del Estado de referencia y que luego sirva de modelo vinculante al resto de Estados miembros, donde se realiza una tramitación nacional simplificada y vinculada por la primera decisión (Tavares da Silva, 2010: 73; Izquierdo Carrasco, 2018: 425). Ese modelo regulativo, articulado sobre la figura del reconocimiento mutuo, no puede ser configurado como un procedimiento descentralizado ${ }^{89}$.

El procedimiento descentralizado no puede confundirse con el procedimiento de adopción de decisiones conjuntas (joint decisions) ${ }^{90}$, donde el procedimiento multilateral da lugar a una única autorización en un procedimiento dirigido por el Estado de referencia. Tras el examen de la solicitud y

89 No comparto la equiparación entre el procedimiento de reconocimiento mutuo y el procedimiento descentralizado realizada por Viñuales Ferreiro (2015: 226).

90 Como precisa De Lucia (2016: 96), la decisión conjunta es una autorización nacional que es el resultado de un procedimiento compuesto en el que participan todas las Administraciones estatales implicadas con un papel de codecisión. Ahí el procedimiento tiene que equilibrar el policentrismo administrativo con la existencia de una única decisión. 
de los documentos presentados por el solicitante a nivel nacional, se desarrolla una fase multilateral en la que intervienen (de forma expresa o implícita) las Administraciones de los Estados concernidos. Solo en ausencia de oposición de las demás administraciones podrá la Administración de referencia otorgar la autorización. Tampoco puede confundirse con el procedimiento de autorización sujeta a reconocimiento mutuo, donde existen diversas autorizaciones interconectadas (en cadena) otorgadas conforme al ordenamiento jurídico de cada Estado miembro. La primera medida solo tiene efectos legales en el país de origen, mientras que la segunda permite que los efectos de la primera se produzcan también en el país de acogida. Aquí existen tantos procedimientos como autorizaciones se otorgan, si bien las Administraciones receptoras se limitan a constatar los resultados de la evaluación llevada a cabo por el primer Estado y, sin repetir la evaluación, proceden únicamente a determinar los efectos en su ordenamiento jurídico, comprobando que la autorización inicial se ajusta a su ordenamiento jurídico nacional (De Lucia, 2016: 97).

El procedimiento descentralizado, por el contrario, debe configurase como un procedimiento administrativo compuesto horizontal (Hofmann, 2019: 18). Y ello porque se requiere, en primer lugar, una conexión jurídica sobre cuya base se puede establecer que la coordinación de los diferentes agentes administrativos se dirige a un resultado final. En segundo lugar, se presenta una falta de autonomía de los subprocedimientos que los componen, debido a su vinculación estructural (Mendes, 2014: 395). La interdependencia de las actuaciones de cada Administración que interviene en este procedimiento implica que cada una de ellas no puede ejercer sus competencias antes de que otra Administración haya concluido la fase previa diseñada (Brito Bastos, 2018: 105). El procedimiento descentralizado da lugar a autorizaciones paralelas otorgadas por cada autoridad nacional, desplegando sus efectos exclusivamente en su propio territorio ${ }^{91}$. El elemento relevante es que cada Administración nacional participa de forma relevante en el procedimiento descentralizado, dirigido por el Estado de referencia, verificando y determinando o rechazando los resultados del examen llevados a cabo por éste antes de que otorgue la primera autorización (De Lucia, 2016: 98). Se produce así una coordinación de las autoridades de los Estados miembros participantes. Si todos comparten la evaluación, se adoptan las diferentes autorizaciones de comercialización con el mismo contenido. La unanimidad en la aceptación de la evaluación justifica la vinculación procedimental de los Estados que participan. La decisión aquí es reglada (vinculante) para ellos. Si

91 Como ocurre, por ejemplo, con las autorizaciones de productos fitosanitarios. Sobre ello, cfr. Chinchilla Peinado (2015: 157). 
existen discrepancias, la decisión es coordinada por la AEM y la Comisión. En la concreta articulación de estos procedimientos compuestos de revisión o de remisión, la Comisión (y la EMA) no está vinculada por las actuaciones de los Estados intervinientes, que tienen aquí la condición de meros trabajos preparatorios (Brito Bastos, 2018: 107). Se configura así como un procedimiento cooperativo o compuesto, donde las Administraciones de los Estados miembros dirigen su actuación para la consecución del interés público de ámbito europeo. Esa participación presenta un carácter agregado, que se proyecta sobre las distintas autorizaciones de comercialización que otorga cada Estado miembro. Funcionalmente no puede analizarse la participación de cada Estado miembro en el procedimiento de forma independiente o aislada (función ordenadora del procedimiento descentralizado).

Por ello, metodológicamente no parece correcto seguir configurando esta autorización descentralizada como una simple variante del principio de reconocimiento mutuo. Y ello porque sus efectos no son la admisión en un ordenamiento nacional de los efectos generados en un ordenamiento interno de otro Estado miembro. En este tipo regulatorio y de ejecución descentralizado no entra en juego el principio de territorialidad y exclusividad del derecho estatal porque lo que se aplica no es una norma de derecho nacional, sino directamente el derecho europeo (normas de derecho secundario y el soft law que lo complementa). La apertura horizontal a los ordenamientos de otros Estados miembros se plasma aquí reconociendo la eficacia supranacional (Agudo González, 2019: 249)92 a la actuación administrativa adoptada de forma colaborativa (valoración científica) por los Estados, pero aplicando no un ordenamiento nacional, sino una norma europea, común y obligatoria para todos los Estados miembros. El criterio de validez de la actuación administrativa es supranacional, tanto en el Estado de referencia como en los Estados concernidos. Se trata así de un modelo que responde al pluralismo normativo (Tavares da Silva, 2018: 446) derivado de la integración europea basado en un constitucionalismo horizontal que adopta como metaprincipio la asunción como propias de las preocupaciones del resto de Estados miembros, valorándose como elemento esencial el consenso (la confianza) en la adopción de autorizaciones, máxime en los sectores donde el principio de precaución como base de la evaluación del riesgo es el criterio rector del análisis material (De Lucia, 2016: 109). Al aplicar el derecho europeo, las correspondientes autoridades de los Estados miembros están sujetas tanto a las obligaciones

92 El concepto de supranacionalidad permite mantener la simetría entre el espacio jurídico europeo (unión administrativa europea) y el espacio de validez y vigencia del derecho europeo 
derivadas directamente del derecho secundario que establecen los procedimientos como a los principios generales del derecho de la UE que se proyectan sobre el procedimiento administrativo y el derecho de defensa ${ }^{93}$. El derecho a una buena administración obliga a esas Administraciones nacionales a realizar una evaluación completa e imparcial de todos los hechos relevantes, a respetar el derecho a ser oído, a adoptar una decisión motivada y a garantizar el acceso a los documentos (Hofmann, 2019: 5).

El reconocimiento y ejercicio de los derechos atribuidos por la autorización de comercialización otorgada a través del procedimiento descentralizado no están sujetos a criterios de validez nacional, a los criterios propios del ordenamiento de cada Estado miembro. Los derechos otorgados a estos operadores son derechos regulados por el derecho europeo. Aquí se produce una relación vertical entre el derecho de la Unión Europea, en cuanto ordenación que atribuye derechos con eficacia supranacional, y los derechos nacionales, en cuanto ordenamientos que regulan el otorgamiento por una Administración nacional de las facultades que tales autorizaciones suponen y garantizan la tutela judicial de ese derecho, no solo por los órganos nacionales del Estado autorizante, sino por los órganos jurisdiccionales del resto de Estados miembros (Agudo González, 2019: 202). La unión administrativa conduce a la unión jurisdiccional, determinando una interpretación de las normas procesales nacionales que garanticen la efectividad de los derechos derivados de las autorizaciones. El principio de doble exclusividad como regla de control judicial (Brito Bastos, 2020: 68) se completa en los procedimientos compuestos por la interdependencia decisional.

La interpretación del procedimiento descentralizado aquí mantenida no supone afirmar que la adopción de una norma de conducta articulada sobre normas procedimentales evita la existencia de discrepancias valorativas (incluidas discrepancias de calado político) (De Lucia, 2016: 113). Es su configuración como un procedimiento en red, multipolar, articulado sobre el principio de precaución, el que permite eliminar en una fase previa las posibles discrepancias. El principio de cooperación leal (art. 4.3 TUE), que aparece como base, no solo de la articulación del procedimiento descentralizado, sino también como base de la articulación del sistema de control judicial, evita posibles decisiones judiciales divergentes. La opción por una ejecución cooperativa del derecho europeo en la autorización de medicamentos garantiza a través de este procedimiento compuesto una aplicación uniforme del derecho

93 Sentencias del Tribunal de Justicia de 9 de noviembre de 2017, Ispas, C-298/16, EU:C:2017:843; de 17 de diciembre de 2015; WebMindLicenses, C-419/14, EU:C:2015:832, y de 22 de octubre de 2013, Sabou, C-276/12, EU:C:2013:678. 
de la Unión Europea, a la vez que se preserva la autonomía administrativa de los Estados miembros (Brito Bastos, 2020: 66). Y esa idea rectora ha guiado las decisiones de los órganos judiciales nacionales cuando han enjuiciado actos adoptados en el procedimiento descentralizado, evitando así una laguna en la vigencia del principio de estado de derecho (en su vertiente subjetiva y objetiva).

\section{Bibliografía}

Agudo González, J. (2019). La articulación de las relaciones jurídicas transnacionales mediante las variantes del reconocimiento mutuo. En J. Agudo González (dir.). Relaciones jurídicas transnacionales y reconocimiento mutuo (pp. 181-310). Cizur Menor (Navarra): Aranzadi.

Alonso de León, S. (2017). Composite administrative procedures in the European Union. Madrid: Iustel.

Bombillar Sáenz, F. M. (2010). Intervención administrativa y régimen jurídico del medicamento en la Unión Europea [tesis doctoral]. Universidad de Granada. Disponible en: https://kutt.it/0larmP.

Brito Bastos, F. (2018). Derivative illegality in European composite administrative procedures. Common Market Law Review, 55, 101-134.

Brito Bastos, F. (2020). An Administrative Crack in the EU's Rule of Law: Composite Decision-making and Nonjusticiable National Law. European Constitutional Law Review, 16, 63-90. Disponible en: https://doi.org/10.1017/ S1574019620000073.

Chinchilla Peinado, J. A. (2015). Las redes administrativas de la seguridad alimentaria en el derecho de la Unión Europea: procedimientos y estructura. En A. Menéndez Rexach (dir). Estudios jurídicos sobre seguridad alimentaria (pp. 143-180). Madrid: Marcial Pons. Disponible en: https://doi.org/10.2307/j. ctv10rr9qr.7.

De Lucia, L. (2009). Amministrazione transnazionale e ordinamento europeo. Turín: Giappichelli.

De Lucia, L. (2016). From mutual recognition to EU authorization: a decline of transnational administrative acts? Italian Journal of Public Law, 8, 90-114.

Domínguez Martín, M. (2020). La coordinación de los sistemas de seguridad social y el desplazamiento de trabajadores en la Unión Europea: derecho aplicable, tutela y colaboración administrativa. Revista General de Derecho Administrativo, 54, 1-35.

Ebbers, H. C., Langedijk, J., Bouvy, J. C., Hoekman, J., Wouter P. C., De Jong, J. P. y De Bruin, M. L. (2015). An analysis of marketing authorisation applications via the mutual recognition and decentralized procedures in Europe. European Journal of Clinical Pharmacology, 71, 1237-1244. Disponible en: https://doi. org/10.1007/s00228-015-1904-1. 
Fernández Gaztea, J. K. (2018). Propuesta de un modelo más preciso para la sistematización de las actuaciones de ejecución del Derecho. Revista de Estudios Europeos, 71, 273-299.

Hofmann, H. (2019). Multi-Jurisdictional Composite Procedures. The Backbone to the EU's Single Regulatory Space. Law Working Paper Series 003. Disponible en: https://doi.org/10.2139/ssrn.3399042.

Izquierdo Carrasco, M. (2018). El impacto del derecho administrativo transnacional en el régimen jurídico de la seguridad de los medicamentos y alimentos. En A. d'Oliveira Martins (dir.). O Direito Administrativo Transnacional (Direito Administrativo Internacional, Europeu e Global) e as suas implicaçoes no Direito Administrativo de Espanha e de Portugal. Actas del XII Colóquio Luso-Espanhol de Professores de Direito Administrativo (pp. 363-444). Lisboa: Universidade Lusíada Editora.

Kyle, M. K. (2019). The Single Market in Pharmaceuticals. Review of Industrial Organization, 55, 111-135. Disponible en: https://doi.org/10.1007/s11151019-09694-6.

Langedijk, J., Ebbers, H. C., Mantel-Teeuwisse, A. K., Kruger-Peters, A. G., y Leufkens, H. G. M. (2016). Licensing failure in the European decentralised procedure. European Journal of Pharmaceutical Sciences, 87, 47-51. Disponible en: https://doi.org/10.1016/j.ejps.2015.10.014.

López de Castro García-Morato, L. (2020). Reconocimiento mutuo de cualificaciones profesionales en la Unión Europea: tutela y cooperación administrativa. Revista General de Derecho Europeo, 51, 86-139.

Mendes, J. (2014). Rule of law and participation: A normative analysis of internationalized rulemaking as composite procedures. International Journal of Constitutional Law 12 (2), 370-401. Disponible en: https://doi.org/10.1093/icon/ mou018.

Ortega Bernardo, J. (2017). El acto administrativo transnacional en el derecho europeo del mercado interior. Revista Española de Derecho Administrativo, 188, 81-124.

Qu, L., Zou, W., Wang, Y., y Wang, M. (2018). European regulation model for herbal medicine: The assessment of the EU monograph and the safety and efficacy evaluation in marketing authorization or registration in Member States. Phytomedicine, 42, 219-225. Disponible en: https://doi.org/10.1016/j. phymed.2018.03.048.

Rodríguez de Santiago, J. M. (2016). Metodología del Derecho Administrativo. Reglas de racionalidad para la adopción y control de la decisión administrativa. Madrid: Marcial Pons.

Röttger-Wirtz, S. y Eliantonio, M. (2019). From integration to exclusion: EU composite administration and gaps in judicial accountability in the authorisation of pharmaceuticals. European Journal of Risk Regulation 10, 393-411. Disponible en: https://doi.org/10.1017/err.2019.32. 
Ruffert, M. (2008). De la europeización del derecho administrativo a la unión administrativa europea. En F. Velasco Caballero y J. P. Schneider (dirs.). La unión administrativa europea (pp. 87-108). Madrid: Marcial Pons.

Schmidt-Aßmann, E. (2003). La teoría general del Derecho administrativo como sistema objeto y fundamentos de la construcción sistemática. Madrid: Marcial Pons.

Schneider, J. P. (2008). Estructuras de la unión administrativa europea: observaciones introductorias. En F. Velasco Caballero y J. P. Schneider (dirs.). La unión administrativa europea (pp. 25-50). Madrid: Marcial Pons.

Siegel, T. (2016). Europeización del Derecho Público. Marco de condiciones y puntos de interacción entre el Derecho europeo y el Derecho (administrativo) nacional. Madrid: Marcial Pons.

Tavares da Silva, S. (2010). Direito administrativo europeu. Coimbra: Imprensa da Universidade de Coimbra.

Tavares da Silva, S. (2018). As actividades de risco ou de perigo, em especial, o regime jurídico dos medicamentos e dos alimentos. En A. d'Oliveira Martins (dir.). O Direito Administrativo Transnacional (Direito Administrativo Internacional, Europeu e Global) e as suas implicaçoes no Direito Administrativo de Espanha e de Portugal. Actas del XII Colóquio Luso-Espanhol de Professores de Direito Administrativo (pp. 445-462). Lisboa: Universidade Lusíada Editora.

Vaughan, S. (2015). Differentiation and Dysfunction: An Exploration of Post-Legislative Guidance Practices in 14 EU Agencies. Cambridge Yearbook of European Legal Studies. 17, 66-91. Disponible en: https://doi.org/10.1017/cel.2015.3.

Viñuales Ferreiro, S. (2015). Las garantías de los administrados en los procedimientos relativos a la autorización de medicamentos en la Unión Europea. Revista de Derecho de la Unión Europea, 29, 223-246. 